\title{
Earthquake time tropospheric wind flow pattern: a supplement to the upper atmospheric preludes during strong Tohoku earthquake event of March 2011
}

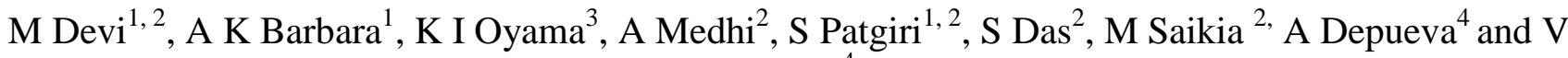 \\ Depuev $^{4}$ \\ ${ }^{1}$ Dept. of Physics, Gauhati University, Guwahati-14, Assam, India \\ ${ }^{2}$ ST Radar Centre, Gauhati University, Guwahati-14, Assam, India \\ ${ }^{3}$ International Center for Space Weather Study and Education, Kyushu University, Fukuoka, Japan \\ ${ }^{4}$ IZMIRAN, Russian
}

\begin{abstract}
Global efforts in identifying earthquake (EQ) precursors through adaptation of seismogenic-modification features imprinted on variabilities of the lower atmosphere, ionosphere and beyond, are now well documented. But the inherent complexities of the physical and dynamical processes of this atmospheric system still pose as challenges in generating a reliable EQ predictive model, therefore novel ideas and inductions of relevant new parameters are always welcome as additional inputs to such study. The paper is framed with these aims by looking into the role of EQ preparatory processes on the lower atmospheric wind flow pattern with special reference to very strong magnitude Tohoku seismic event of March 2011. The analysis however is not quantitative yet, but it attempts to provide an additional prelude parameter along with already identified features induced by this EQ on Total Electron Content (TEC), ionisation density (foF2) of upper atmosphere and structure constant parameter $\left(\mathrm{Cn}^{2}\right)$ of lower atmosphere. The wind being considered as a rich source carrying atmospheric disturbance information, the paper discusses how the likely response of the wind system (to EQ) could provide seismic time dynamical information of the atmospheric environment for building up future comprehensive EQ predictive model.
\end{abstract}

Keywords: Tohoku Earthquake; Tropospheric wind flow; $\mathrm{Cn}^{2,} \mathrm{TEC}$; foF2. Preludes. 


\section{Introduction}

The study on seismogenic effects on the global environment consists of wide angle of views, starting from traditional one to geological and of late the electro-magnetic (EM) approaches, to name a few. The availability of wide spectra of frequencies in EM platform offers multiple choices to utilize the need based ranges of frequencies as probing carriers of EQ effects while propagating through different atmospheric environment; this is an indirect mode of earthquake induced observations and is our choice of approach of the study here.

In this mode of study, the atmospheric strata from troposphere to upper atmosphere and beyond act as experimental laboratories and EQ induced effects on physical parameters of respective sphere carried by the probing signals are then examined in search of precursive features. The physical quantities of the atmosphere generally selected for earthquake studies are temperature, pressure, water vapour of lower atmosphere along with ionisation density, electron/ion temperature, Total Electron Content(TEC) of the upper atmosphere [Tadanori 1998; Devi et al., 2001; Liu et al., 2001; Devi et al., 2004; Pulinets and Boyarchuk 2004; Devi et al., 2008 ; Oyama et al., 2008; Devi et al., 2010 a; Oyama et al., 2011; Sun et al ., 2011; Liu et al., 2014 ; Smrinov et al., 2015 ; Oyama et al., 2016 ; Parrot and Li 2018 ; Devi et al., 2019 ]. These parameters monitored simultaneously through proper selection of probing frequencies, can offer earthquake induced responses with wealth of information for understanding physics and system dynamics. Added to these quantities, parameters of lower atmosphere like, IR emission, Radio Refractive Index (RRI ), Structure Constant Parameter $\left(\mathrm{Cn}^{2}\right)$ are also utilised [Oznov and Freund 2004; Devi et al., 2007; Devi et al., 2012 ; Devi et al., 2015 b; Medhi et al., 2015; Medhi et al., 2018, ] as supports to such analyses.

In this article our aim is to examine whether EQ induced effects could be observed in tropospheric wind circulation system around the epicentre of this strong Tohoku event, so that a comprehensive view of the seismogenic effects on the entire gamut of atmosphere could be made along with the EQ time features on TEC, ionisation density as already available for this event [Devi and Barbara 2012; Devi et al., 2013; Takla et al., 2013 ; Oyama et al., 2019]. We will not go in to the further details of the information extraction approaches from these monitored parameters but, the materials relevant to each mode of observation will be presented in brief, at the respective article when necessary. 


\section{Analysis}

TThe exercise presented in this paper is related to the earthquake Tohoku (defined already in the aim), that occurred on March 11, 2011, a nine magnitude earthquake that shook northeastern Japan, at 2:46 p.m. local time (5:46 a.m. UTC), which was preceded by number of foreshock initiated by the another strong event of $\mathrm{M}=7,3$ of March 9. The epicenter position of the earthquake was $38.29{ }^{\circ} \mathrm{N}, 142.37{ }^{\circ} \mathrm{E}$ that lies 72 kilometers east of Tohoku is shown in Figure 1a and large number of aftershocks (more than 80) that followed the main shock are displayed in Figure 1(b). The strong shaking accompanied with deadly Tsunami had caused untold devastations but looking into the other angle of view as fallout of this $\mathrm{EQ}$, is the efforts of innumerable scientists in bringing a solid number of techno-scientific knowledge based information, through multi-dimensional study on the Tohoku event, so that more reliable EQ warning system could be framed in future, through adaptation of the acquired knowledge
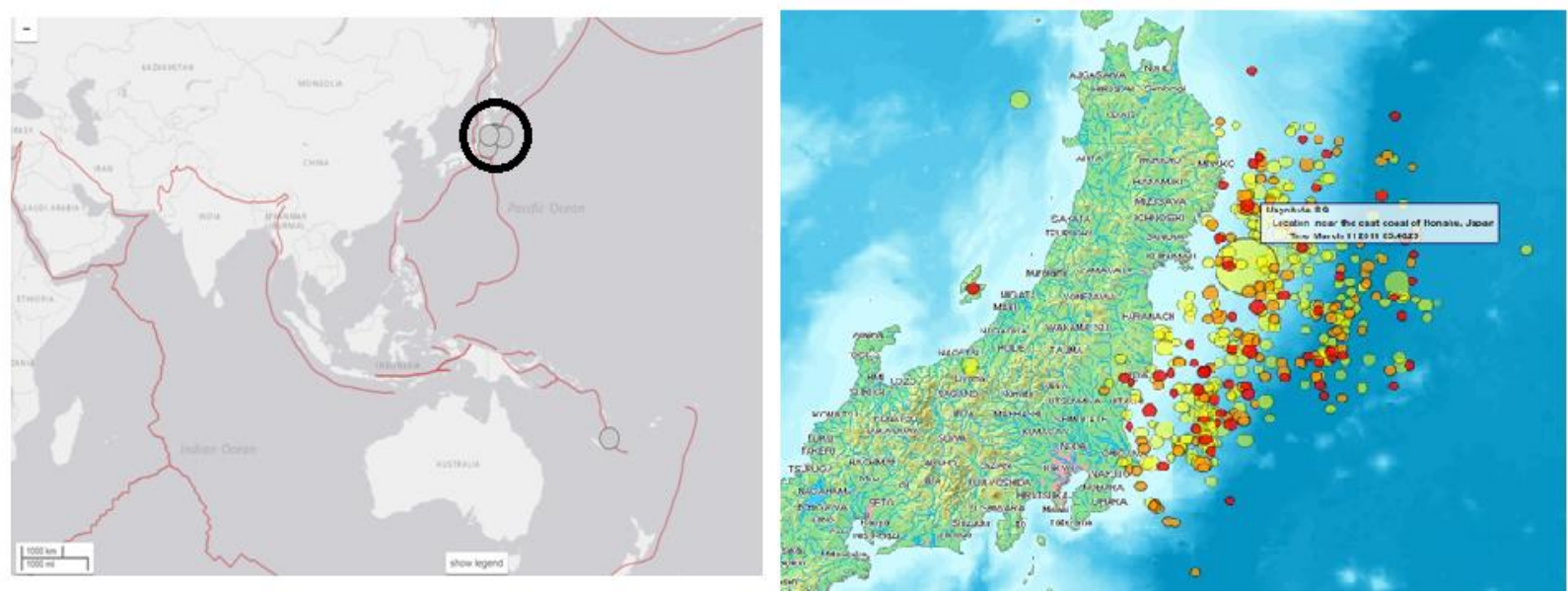

Figure 1: (a) Epicenter of Tohoku earthquake: Date 11.3.2011, M=9.0 proceeded by M=7.3 EQ of 9.3.2011 and (b) A large clusters of earthquakes as aftershocks.

We will present here multi-parameter observations based on the responses of lower /upper atmosphere to the Tohoku EQ, starting with ionization density and TEC of upper atmosphere, followed by tropospheric variabilities like the RRI and $\mathrm{Cn}^{2}$, and finally we will display tropospheric wind flow pattern around the EQ epicentre. 


\subsection{Ionization density and TEC}

The ionosphere responses to seismic preparatory processes are complex function of EQ magnitude, latitude. longitude of the epicentre in the geomagnetic status and also with solar activity [Gershenzon and Gokhberg, 1994; Depueva et al., 2007; Devi et al., 2008; Oyama et al., 2011; Devi et al., 2010(a); Liu et al., 2014 ]. Scientists and researchers are then turning their attention to the Earthquake time Equatorial Anomaly (EEA) effect towards explanation to EQ time modifications in ionization density and electron content [Devi et al., 2011; Devi et al., 2015a; Ryu et al., 2014; Ryu et al.,2016; Devi et al., 2018] specially for equatorial and low latitude seismic events. Even, expansion in the Earthquake time Equatorial Anomaly Crest (EEAC) is also possible as presented by [Devi et al., 2015a] through TEC analysis during Nepal EQ of $\mathrm{M}=7.9$ that struck $77 \mathrm{~km}$ northwest of Nepal's capital Kathmandu at 0611 hrs GMT on 25 April . Further, there are evidences of growth of EEA, significantly at the longitude zone of a mid- latitude EQ epicenter [Devi and Barbara 2012; Devi et al., 2013; Ryu et al., 2014; Ryu et al., 2016], where indirect effects of tropospheric contributions to the density modifications were also noted. Two factors finally considered significant in modifying either ionization density or TEC are (1) Anomaly effect and (ii) contribution of tropospheric indirect effect, at least for the above qualified epicenter locations.

With this background and aims, ionization density and Global Total Electron Content (TEC) profiles prior to, during and after the Tohoku earthquake will first be presented from the available reports that will be followed by tropospheric wind flow analysis.

\subsubsection{Ionization density variations during Tohoku $E Q$}

An earthquake of magnitude $\mathrm{M}=9$, as covers more than $4500 \mathrm{~km}$ as its preparatory area [Dobrovosky et al., 1979], multi-station data are necessary to identify ionospheric responses to the event like the Tohoku. The study zone thus selected here is from $54^{\circ} \mathrm{N}$ to $34^{\circ} \mathrm{S}$ over longitude zone $140 \pm 10^{\circ} \mathrm{E}$, taking foF2 data from ionosonde operated over the selected zone. Figure 2 and Figure 3 display the stations covered for the analysis and table I provides the coordinates of some of the selected stations. 


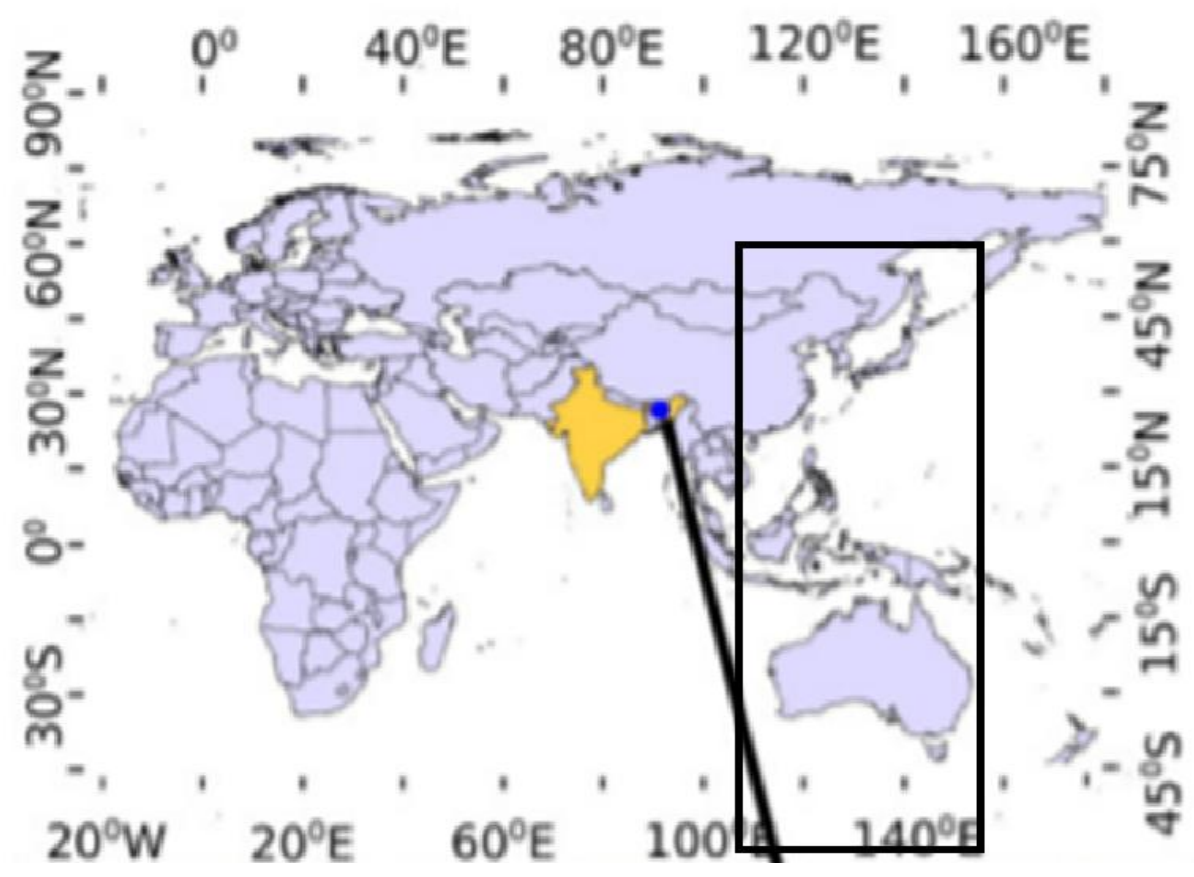

Figure 2: Map displays the rectangular area covered for ionospheric foF2 (density) study, the blue dot is the GPS station at Gauhati University

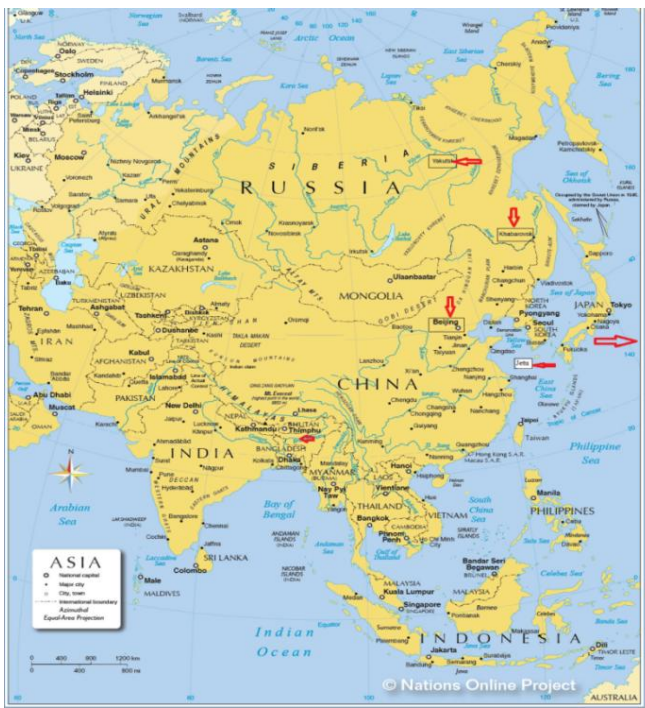

(a)

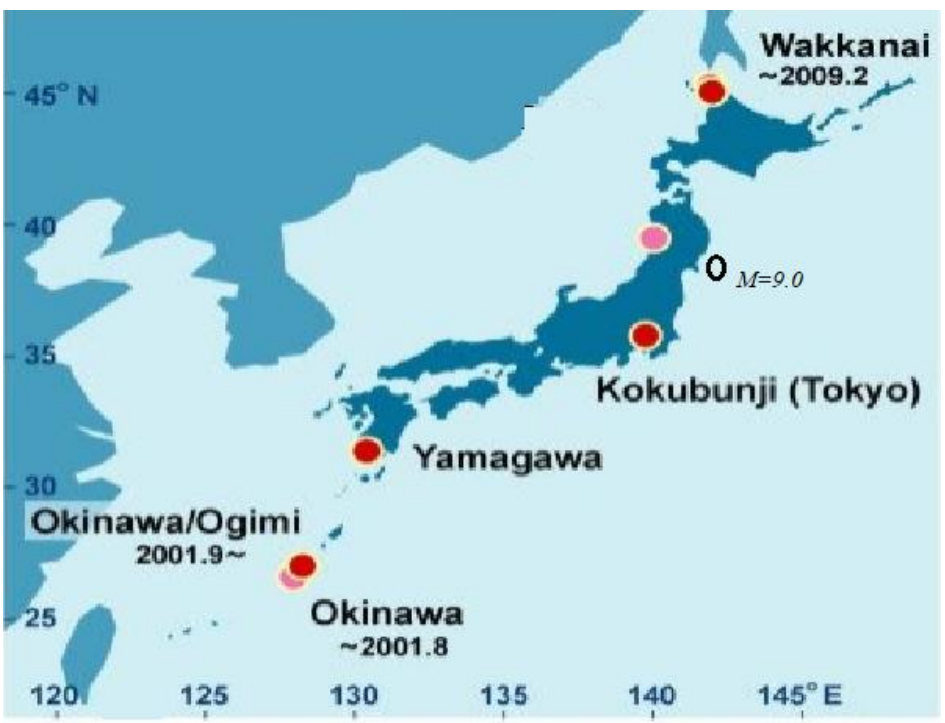

(b)

Figure 3: (a) Map displays the location of stations for ionospheric foF2 (density) study and Figure (b) provides the all selected stations for this study over Japan: a close up view. The stations of the southern hemisphere included in this analyses, are not shown here. 
Table I : Presents the coordinates of stations over Japan and of southern hemisphere stations that are not shown in the map (Figure 3).

\begin{tabular}{llll}
\hline Station (name) & Latitude (geographic) & Longitude ${ }^{\circ} \mathrm{E}$ & Latitude (geomagnetic) \\
\hline Wakkanai & $45.4^{\circ} \mathrm{N}$ & 141.7 & $36.99^{\circ} \mathrm{N}$ \\
Kokubunji & $35.7^{\circ} \mathrm{N}$ & 139.5 & $27.17^{\circ} \mathrm{N}$ \\
Yamagawa & $31.2^{\circ} \mathrm{N}$ & 130.6 & $22.03^{\circ} \mathrm{N}$ \\
Okinawa & $26.3^{\circ} \mathrm{N}$ & 127.8 & $17.03^{\circ} \mathrm{N}$ \\
Darwin & $12.45^{\circ} \mathrm{S}$ & 130.95 & $21.21^{\circ} \mathrm{S}$ \\
Townsville & $19.63^{\circ} \mathrm{S}$ & 146.85 & $26.85^{\circ} \mathrm{S}$ \\
Brisbane & $27.53^{\circ} \mathrm{S}$ & 152.92 & $33.91^{\circ} \mathrm{S}$ \\
Canberra & $35.32^{\circ} \mathrm{S}$ & 149.00 & $42.09^{\circ} \mathrm{S}$ \\
\hline
\end{tabular}

\subsubsection{Analysis technique:}

The approach involved here is the extraction of anomalous features from the critical frequency / ionization density of $\mathrm{F} 2$ layer, i.e., foF2/NmF2 of each day from the quiet day mean of the month, of the respective stations. The following equation is used for this purpose that provides magnitude of deviation of each day density NmF2 (or foF2) from the respective mean value of the month:

$$
\frac{N m F 2-N m f 2(\text { mean })}{N m F 2(\text { mean })}
$$

The analysis output is presented in Figure 4. Here, NmF2 (mean) is calculated for each hour of a month (quiet day) for every station and corresponding $\mathrm{NmF} 2$ of that hour for any day is subtracted from the respective mean by using the equation 1 , positive, negative modulations in density around the EQ day depending on the responses are then obtained ( Figure 4). The density however is also likely to get modified by magnetic storm that happened to coincide on the day of the EQ. Therefore, one gets a view from Figure 4, that negative effect on density is more intense at higher latitudes may be by the magnetic storm effect and as we move to lower latitudes, the positive responses (on density) becomes more significant perhaps as a result of EQ preparatory processes.

So it was necessary to isolate the earthquake effect on density, from the geomagnetic storm ambiances, before we could interpret the observation of Figure 4. In such an attempt, we present in Figure 5, the density modulation (Total Electron Content) features of Gauhati, an Appleton Anomaly crest station, with storm index DST from March 01 to March 16, 2011 covering the Tohoku EQ event of March 11. The diurnal peak value of electron content was seen not to be affected by two magnetic storms that occurred 
during this period (March 1 and March 11,) but an enhancement in TEC on March 7 followed by a significant decrease in its value on March 9 (the strong pre shock day) was an indication of impending EQ on $9^{\text {th }}$, after [Devi et al., 2010b and Devi et al., 2013]. This process further continued with sudden enhancement in density on March 10 , followed by a decrease in its value on March 11, coinciding with the day of main Tohoku event with $M=9$. The role of EQ preparatory processes on density at this anomaly station is further supported by Global TEC features as briefed in the next article. The EQ days are marked by red strips in Figure 5.
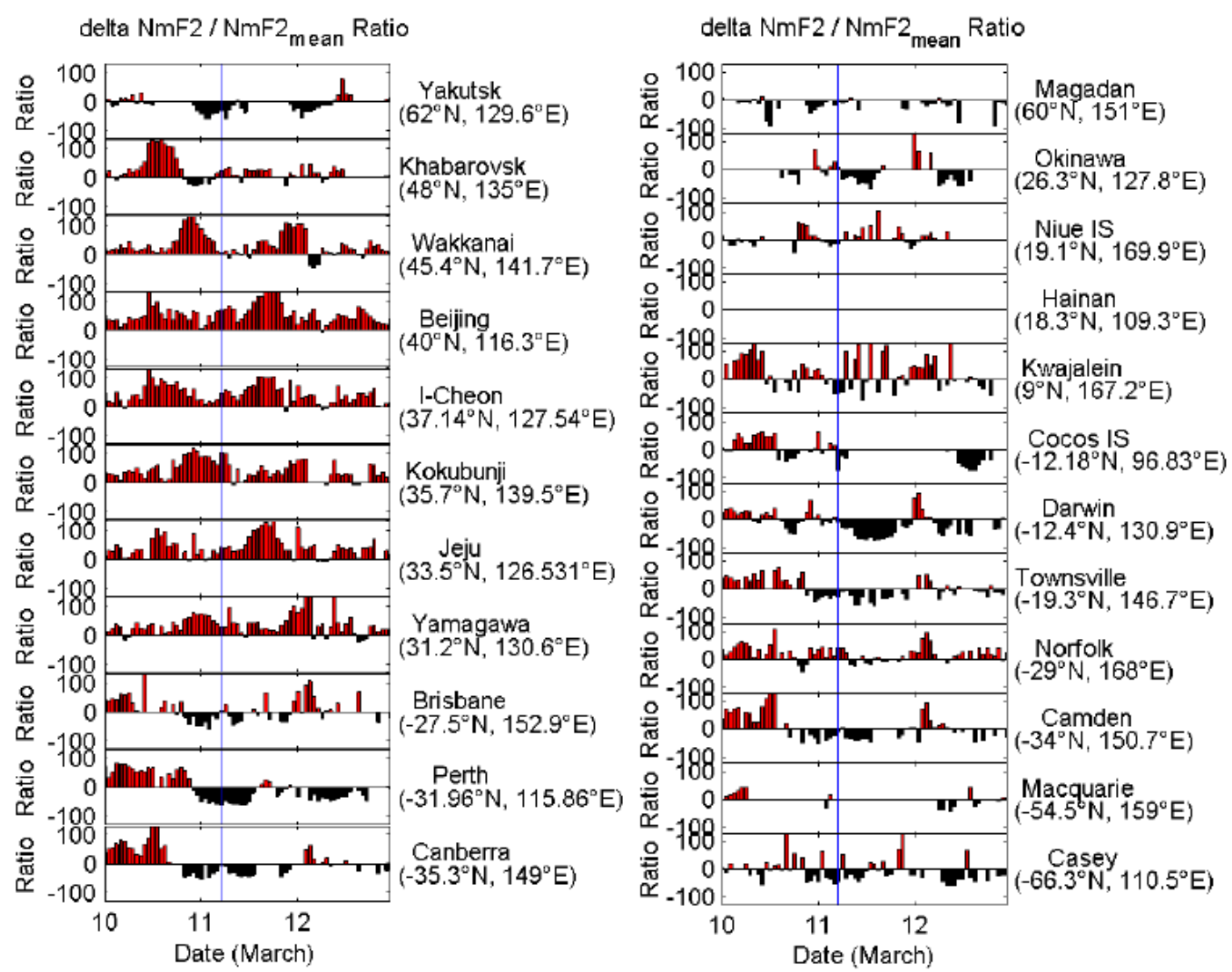

Figure 4: foF2 variations over a wide latitude zone (after Oyama et al., 2019)

Next, addressing this problem of identifying EQ responses on density in geomagnetic storm ambiances, we present in Figure 6 the NmF2 diurnal peak variations with DST values covering the EQ day for a few stations [after Devi et al., 2014 ] It is observed that at high latitude stations the negative trend in density profile with increase in DST magnitudes (negative) prior to and on the EQ day (March 11 with DST -90) continued without showing any effect of EQ, but at the relatively low latitude stations like Beijing, L Cheon and Jetu, the negative storm time density trend developed a break around EQ day 
due to presence of a positive seismic induced response. We will not present here the detailed technique and analysis adopted for this process of analysis. The conclusion that came up from this study is that seismogenic response to atmospheres is more significant at low-mid latitude stations compared to that of a high latitude one, especially in a geomagnetic disturbed environment.

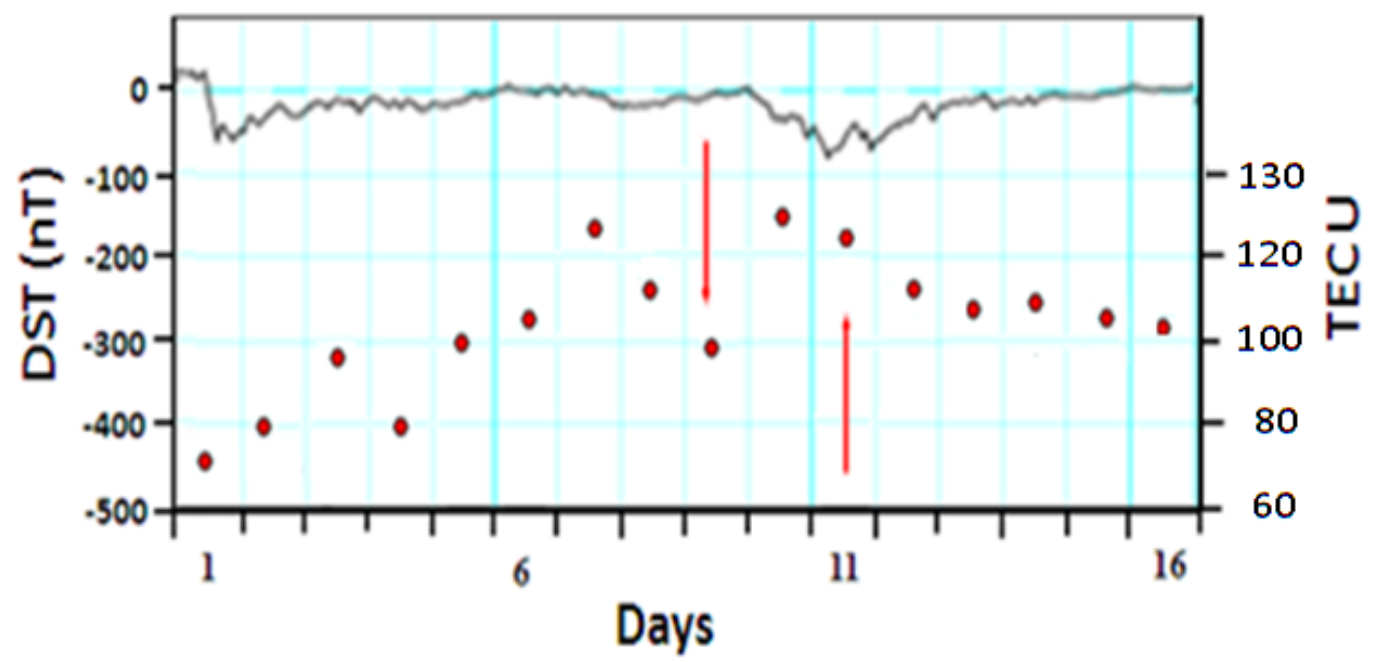

Figure 5: Variations in DST magnitudes from March 1 to 16, 2011, along with those of noon time TEC peak (shown as red dots and EQ days by red lines) (after Devi and Barbara 2012)

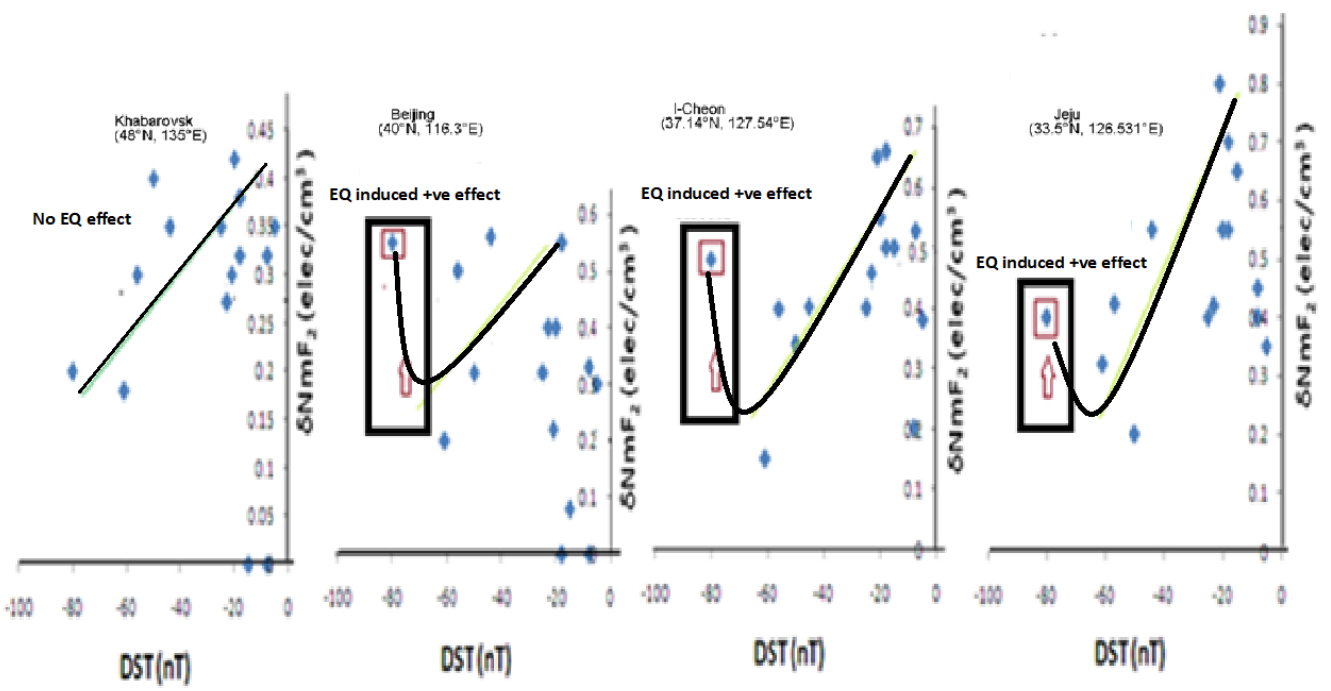

Figure 6: DST - ðfoF2 relation , covering five days prior to the Tohuku EQ event of March 11. The rectangle and the arrowhead in (b). (c) and (d) indicate the break point in DST - ðfoF2 curve, due to the EQ effect (after Minakshi Devi et al., 2014). Note the latitude of the stations, EQ effect on density was up to Beijing but at Khaberovsk $\left(48^{\circ} \mathrm{N}\right)$ magnetic storm contributions are only present. 


\subsubsection{TEC variations during Tohoku EQ}

Global TEC profiles are regularly monitored by us and catalogued in search of EQ effect specially on equatorial anomaly features. To identify the development of normal daytime Equatorial Anomaly position and its diurnal shift in longitude as the time moves, in Figure.7, two quite-time TEC maps one for 06 UT and the other at 13 UT are presented. The anomaly appears as high TEC contour in Figure 7 and develops during daytime in a normal/quiet day. Therefore, in longitude sector of $180^{\circ} \mathrm{E}$ (Figure $7 \mathrm{a}$ ), the anomaly was formed at 3 UT (around $15 \mathrm{hrs}$ LT ) but disappeared at night ( 13 UT) on this sector but showed its appearance at around $10^{\circ} \mathrm{E}-20^{\circ} \mathrm{E}$ i.e., at day-time longitude zone (around $1400 \mathrm{hrs} \mathrm{LT}$, Figure $7 b)$.
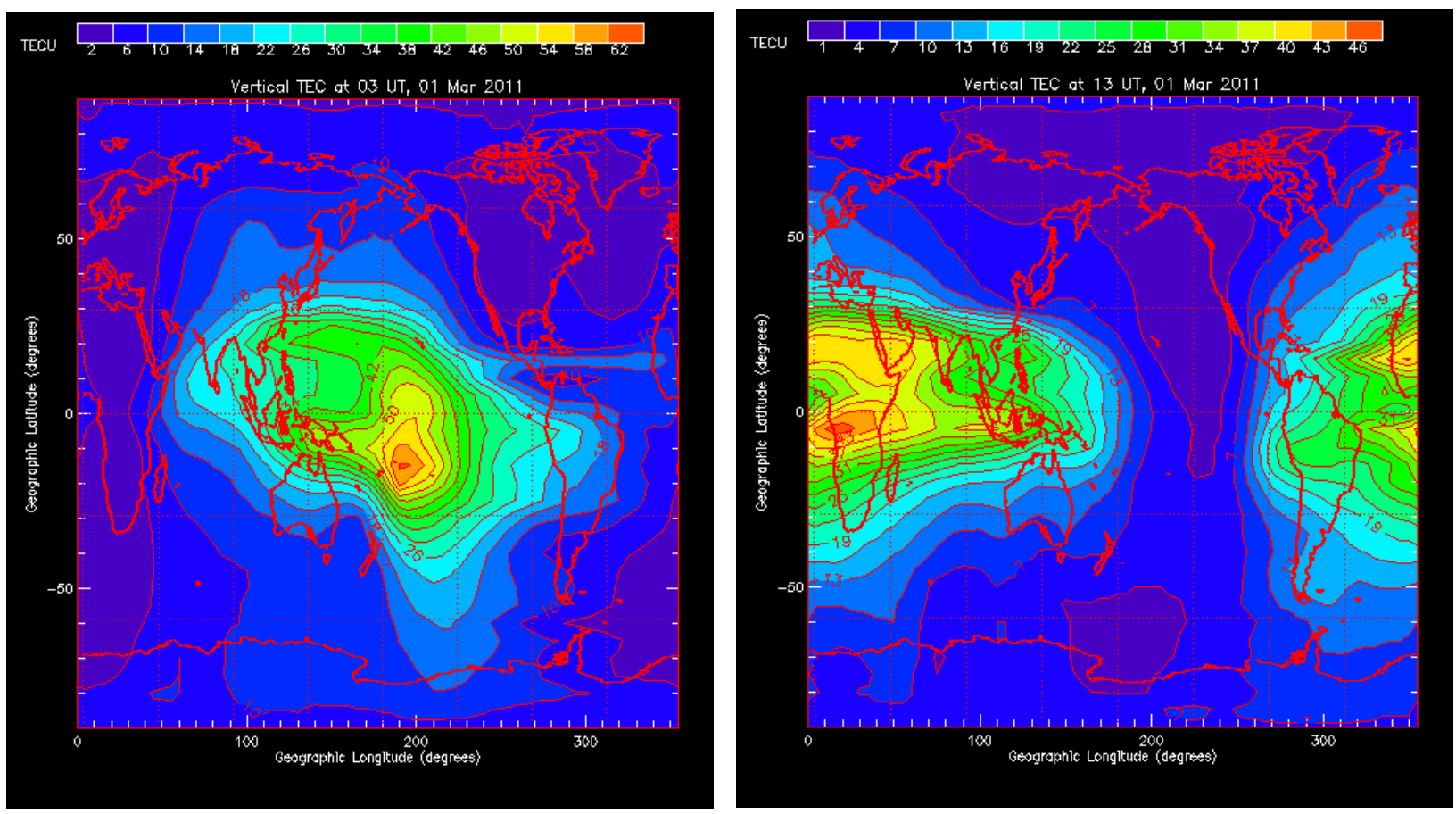

Figure 7 : (a) Normal Equatorial Anomaly (NEA) is seen at $3 \mathrm{UT}$ in $180^{\circ} \mathrm{E}$ longitude ( $15 \mathrm{LT}$ ); (b) shows shifts in the NEA position to $10^{\circ} \mathrm{E}-20^{\circ} \mathrm{E}$ at $13 \mathrm{UT}$ (LT $14 \mathrm{hrs}$ ).

Therefore Equatorial Anomaly being a daytime phenomenon specially well developed during equinoxial seasons, its appearance during night hours in $130^{\circ} \mathrm{E}-140^{\circ} \mathrm{E}$ longitude ( UT 10/11/12 hrs) from March 5,201 (Figure. 8, note presence of NEA up to March 4) onwards, received attention as special event. This anomaly was appreciably strong till March 8, but its sudden wreaking on March 9 
(Figure 8e), has provided supportive clues to its possible association with an impending EQ as per our earlier prelude definition i.e., "enhancement in density followed by depletion" (Devi et al., 2010b). So we defined it as Earthquake time Equatorial Anomaly (EEA) [Devi et al.,2013 ] and predicted an EQ to occur on March 9, which was infect the actual day when the M=7.3 EQ shook Japan ( Figure 5). A strong growth of EEA again on March 10, provided a warning signal of another impending EQ at the same longitude sector and with consequent weakening its strength just prior to the massive Tohoku EQ ( Figure. $8 \mathrm{~g}$ ) we did forecast a strong EQ in $130^{\circ} \mathrm{E}-140^{\circ} \mathrm{E}$ longitude sector on March 11 , the date synchronizes with the Tohoku EQ. So, the Anomaly effect came as a pointer to the prediction of an EQ event but for identifying the epicenter position, we adopt a special approach which is briefly discussed in the following article.

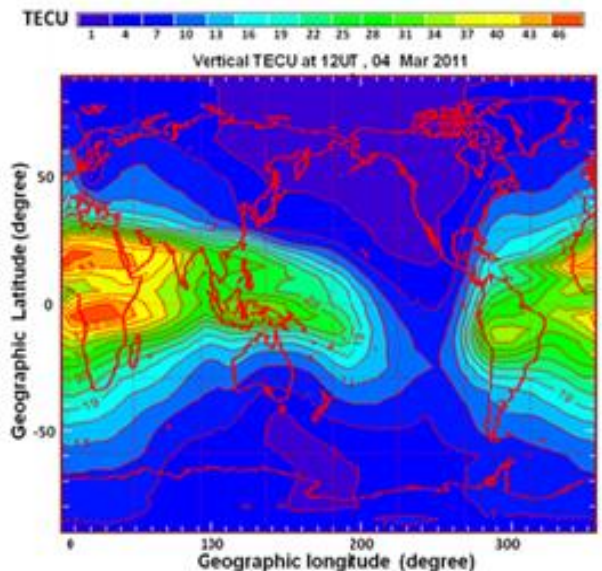

(a)

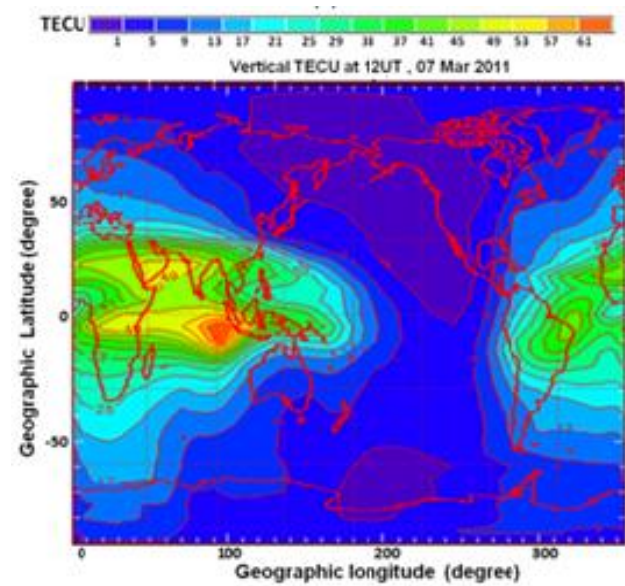

(c)

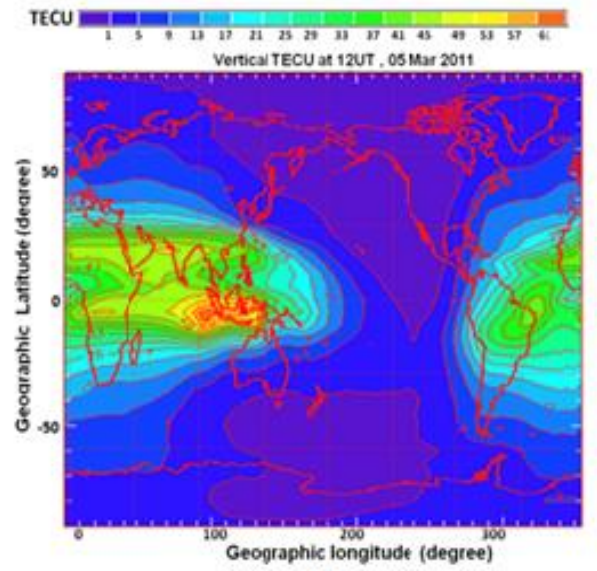

(b)

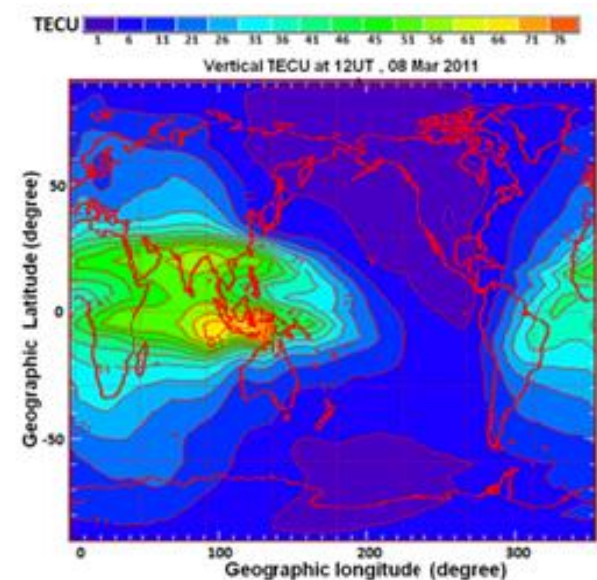

(d) 


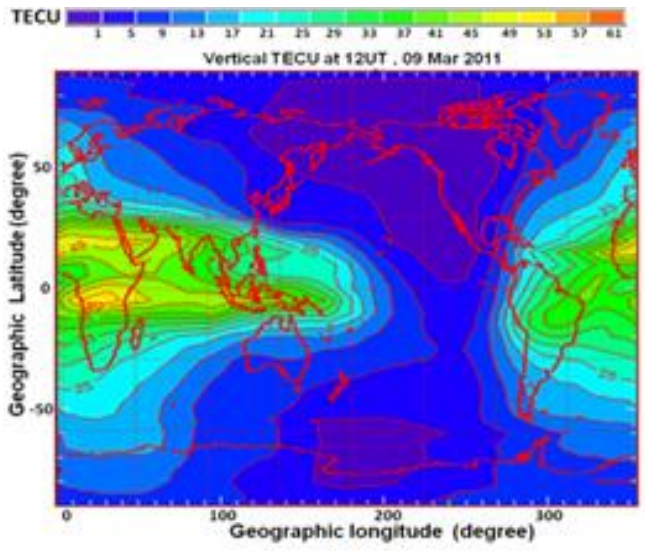

(e)

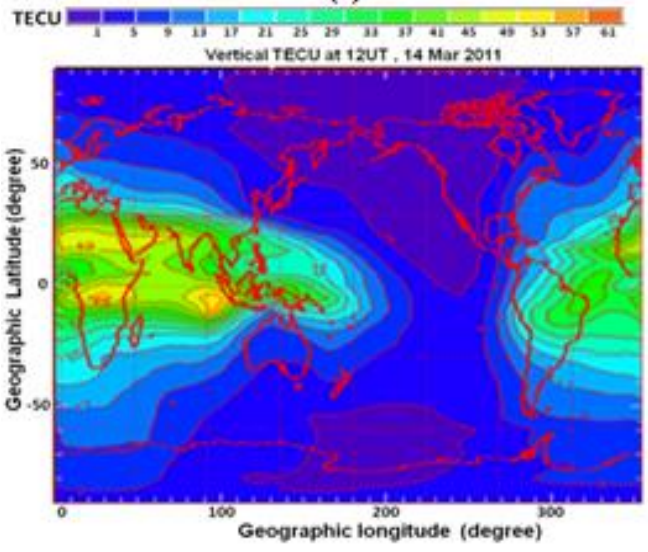

(g)

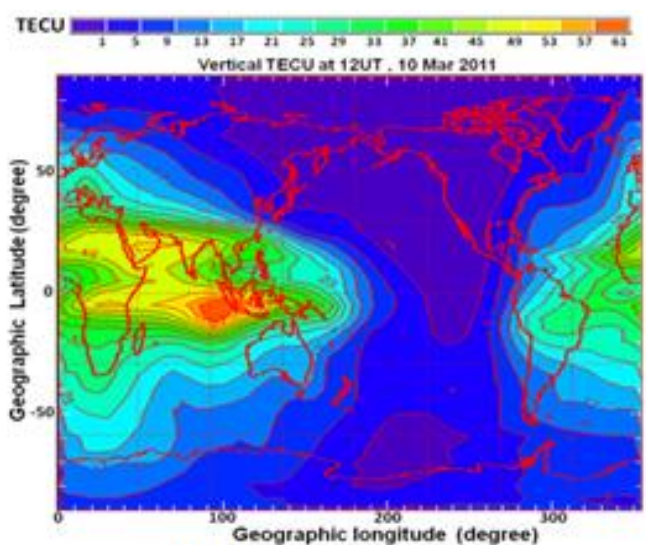

(f)

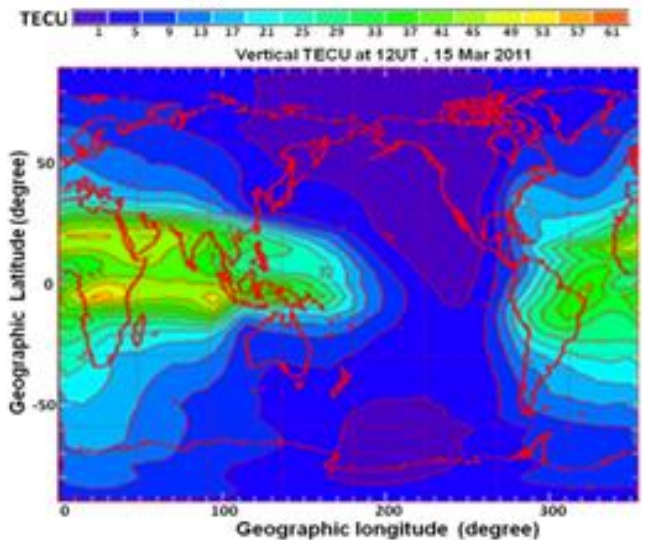

(h)

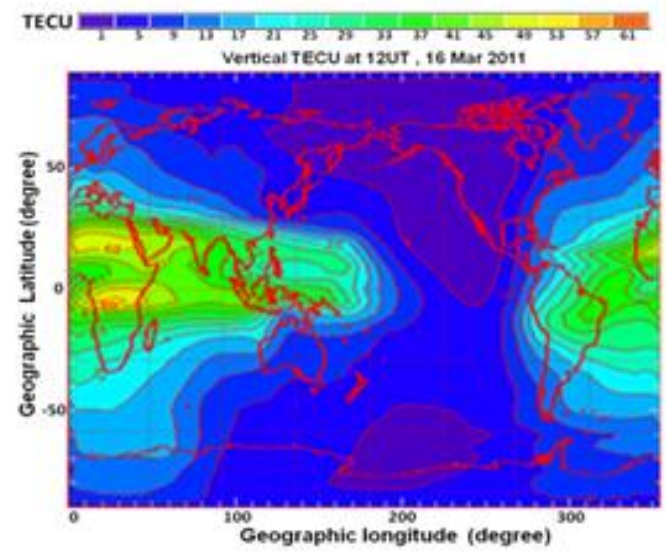

(i)

Figure 8: TEC global map displaying (a) development of NEA at around $20^{\circ} \mathrm{E}$, and no anomalous signature at 120 $\mathrm{E}-130 \mathrm{E}$ (night sector ) 6 days prior to EQ ;(b-d) growth of EEA (at $110^{\circ} \mathrm{E}-140^{\circ} \mathrm{E}$ ) as Japan EQ of March 9, 2011 approaches ;(e) disappearance of EEA and growth of NEA on the day of the EQ; (f) re-development of EEA prior to the massive Tohoku EQ of March 11 and (g-i) gradual decay of EEA strength and recovery of NEA after the EQs. (Devi et al., 2013). 


\subsection{3 : Identifying the epicenter position of Tohoku EQ}

Along with global TEC, we have operated a GPS set up at Gauhati University (Figure 1) and regular analysis of TEC (oblique) shows anomalous appearance of satellites from beyond the normal Field of View (with the receiver at Gauhati) from March 5. In Figure 9 and Figure 10, we present how the satellites azimuthal status gets modified as time moves towards the Tohoku EQ event. The anomalous appearances of such satellites were also noted by Devi et al., [2010b] during Wuhan EQ which they have associated with seismogenic affect in lower atmosphere through enhancement of RRI and effective earth radius factor $(\mathrm{k})$. They have also shown that by methodical conversion of azimuthal positions of these anomalous satellites, the epicenter position i.e., its latitude and longitude could be identified. In this Tahoku event the significant satellite passes are seen from azimuth less than 50 and greater than 320 , which were usually not observed by normal Field of View (FOV) (as marked in the Figure 9) and also we observed that these satellites contributed to significant enhancement (pseudo) in TEC (Figure 10). The azimuth status of these anomalous satellite on conversion to respective latitude/longitude positions, points to $140^{\circ} \mathrm{E}$ and $34^{\circ} \mathrm{N}$, almost to the Tohoku epicenter location.
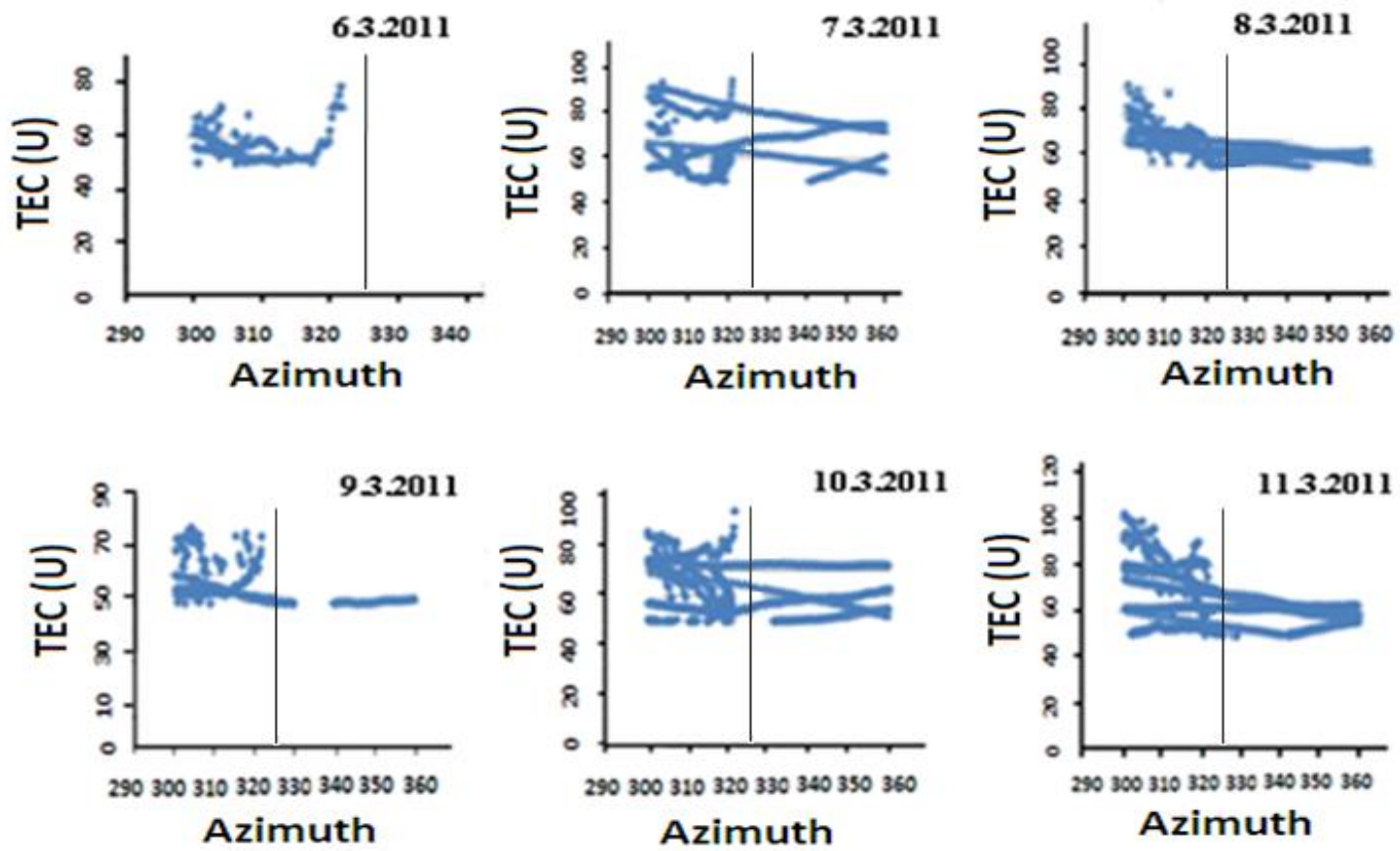

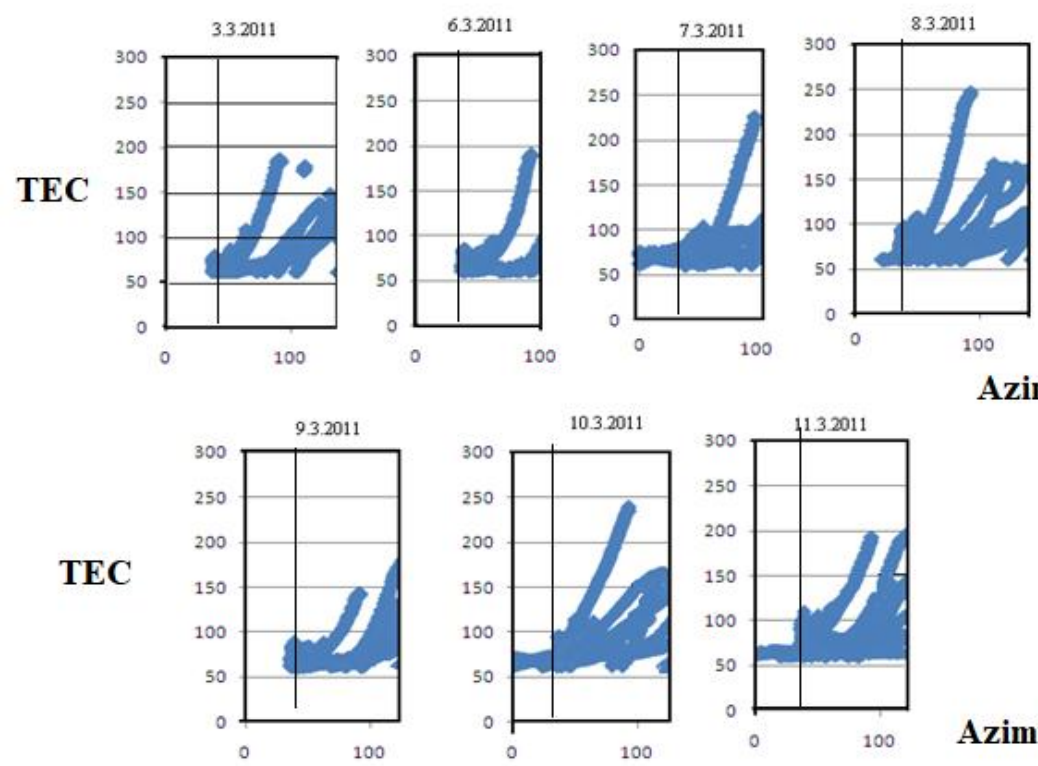

Azimuth

Figure 9 : Large number of satellite passes from azimuth $>320$ and less than 50 (marked in the figure) were seen by the GPS receiver at Guwahati on March 7 and 10' 2011, before the strong Japan EQs of March 9 and 11.

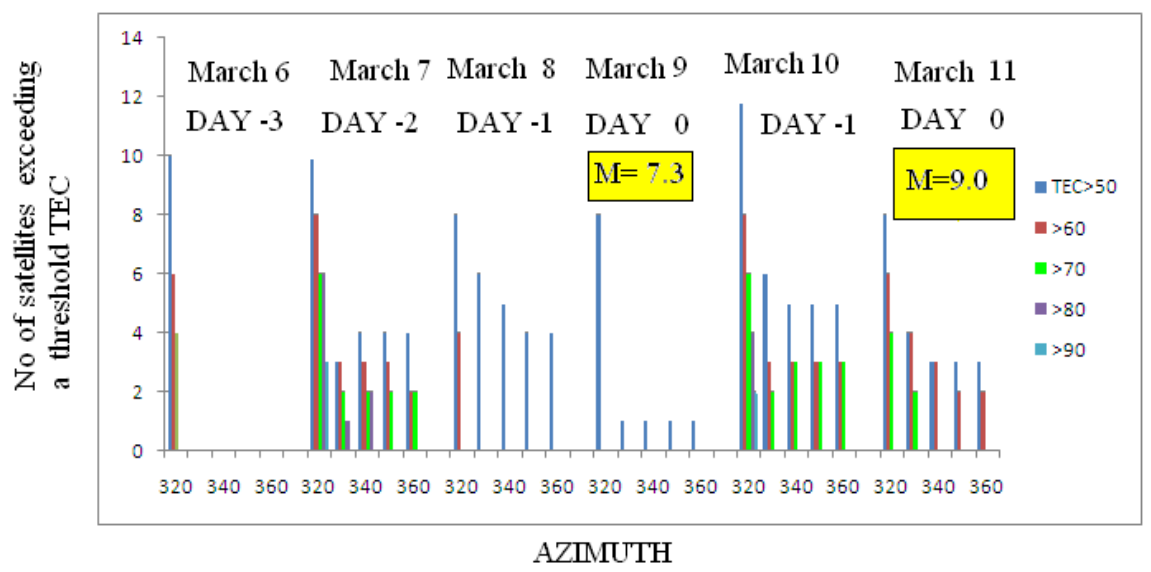

Figure 10: Note the high TEC records obtained through satellites that appeared from beyond the normal Field of View (after Devi et al., 2013).

\subsection{4: Indirect effect of troposphere in EQ time TEC modulation:}

The above observations suggest that FOV of GPS gets modified before an EQ. One of the significant parameters in such modification is RRI (Radio Refractive Index), related to refractive index " $n$ " of the atmosphere .The change of ' $n$ ', being very small, a factor $N=(n-1) \times 10^{6}$, the Radio Refractive Index 
(RRI) is defined along with its gradient $\mathrm{dN} / \mathrm{dh}$ to represent an atmospheric status. The RRI depends on the temperature, humidity and pressure in a complex relation as given by equation (2) and the relation between ' $k$ ' the effective earth radius and RRI gradient is expressed by equation (3)

$$
\begin{gathered}
N=\frac{77.6}{T}\left(P+4810 \frac{e}{T}\right) \\
K=\frac{a_{e}}{a}=\frac{1}{\left(1+a \frac{d N}{d h}\right)}
\end{gathered}
$$

Any change in RRI/km from the normal day will increase or decrease radio link hops by modifying the effective earth radius $(k)$ and hence the Field of View of Trans- receiving setup Thus, the magnitude of $\mathrm{dN} / \mathrm{d} h$ determines the prevailing atmospheric propagation status. We therefore calculate RRI values required to increase the FOV of the trans -receiving environment, when satellites at distance of $7000 \mathrm{~km}$ (LOS between GU and epicenter) may come in view of the GPS at GU. The Table II shows that the RRI values need to be increased by $12.66 \%$, to attaining this status. The observed changes in RRI values by more than $12 \%$ ( not shown here the calculation ) prior to the Tohoku event support that in such favorable background a large number of satellites, beyond the standard FOV, came in to view of the receiving antenna at $\mathrm{GU}$ prior to the Japan $\mathrm{EQ}$.

Therefore the indirect mode of tropospheric contribution to the apparent modification in density, results to identification of the epicenter.

Table II: Shows how the changes in RRI of the troposphere are associated with variation in azimuthal status during EQ (after Medhi, 2016)

\begin{tabular}{|c|c|c|c|}
\hline $\begin{array}{c}\text { Azimuth angle } \\
(\text { degree })\end{array}$ & RRI & $\begin{array}{c}\text { Increased in RRI } \\
(\%)\end{array}$ & $\begin{array}{c}\text { Propagation } \\
\text { distance }(\mathrm{km})\end{array}$ \\
\hline $90-300$ & 300 & 12.66 & 7000 \\
\hline $50-360$ & 339 & & \\
\hline
\end{tabular}




\subsubsection{Tropospheric parameter modification by the Tohoku EQ}

The tropospheric indirect contribution to the anomalous enhancement in TEC,-triggers a series of further analysis invoking lower atmospheric parameters in EQ time lithosphere/atmospheric coupling studies [Devi et al ., 2013; Devi et al., 2015 b, Devi et al., 2019 a ; Devi et al., 2019 b]. One of such varibilites considered here is the structure constant $\mathrm{Cn}^{2}$ [ Medhi et al., 2018] because it involves all tropospheric physical quantities as defined by equations 4 and 5 .

$$
\begin{gathered}
C n^{2} \equiv a^{2} \infty^{\prime} l_{0}^{\frac{4}{3}} M^{2} \\
M=-77.6 \times 10^{-6}\left(\frac{P}{T}\right)\left(\frac{\partial \ln \theta_{T}}{\partial Z}\right)\left[1+\frac{15500}{T}\left(1-\frac{1}{2} \frac{\partial \ln q / \partial Z}{\partial \ln \theta_{T} / \partial Z}\right)\right]
\end{gathered}
$$

$\mathrm{T}$ is the ambient temperature in $\mathrm{K}$,

$\mathrm{P}$ is the pressure;

$\mathrm{q}$ is the specific humidity

$\mathrm{Z}$ is the height in meter

$\theta_{\mathrm{T}}$ is the potential temperature given as

$$
\theta_{T}=T\left[\frac{P_{0}}{P}\right]^{0.3}
$$

Where $\mathrm{P}_{0}$ is the standard atmospheric pressure.

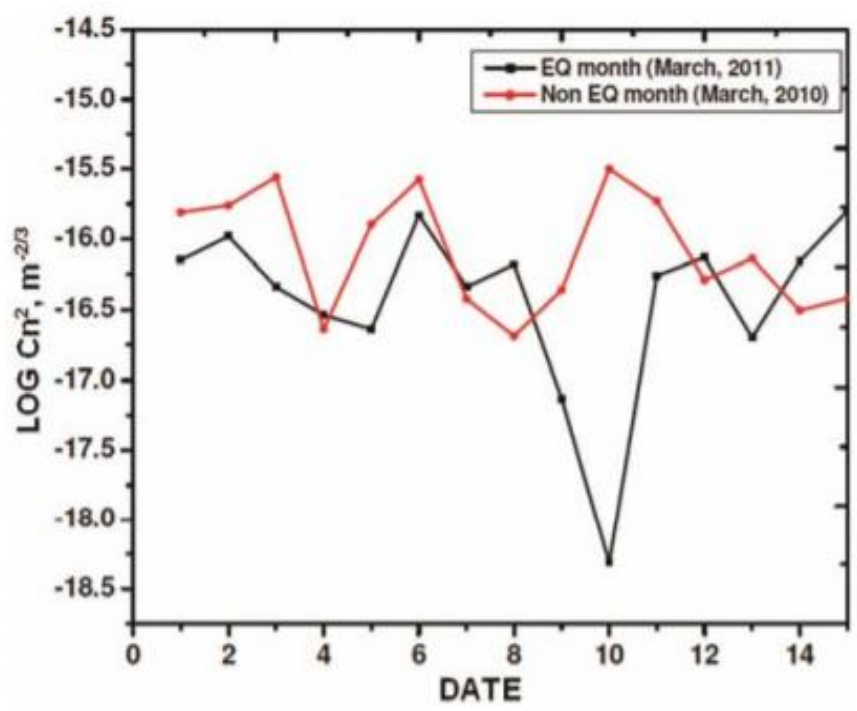

Figure 11: $\mathrm{Cn}^{2}$ features: Note the drop in its magnitude parameter prior to the Tohoku EQ (after Medhi et al., 2015) 
For the calculation of $\mathrm{Cn}^{2}$, all the required parameters of equation (4) are taken from radiosonde observation over the epicenter and structure constant profiles are drawn for earthquake free days of March 2010 as comparison with those of March 2011, the earthquake month .The results presented in Figure 11 show a significant drop in $\mathrm{Cn}^{2}$ magnitude prior to this strong Tohoku event (Figure 11), a direct responses of troposphere to lithospheric dynamics during EQ preparatory processes.

These results thus provide supportive inputs to look for anomaly features in other tropospheric parameters specially in wind circulation pattern during this event as wind flow carries with it the background information. The next article covers this aspect.

\section{Wind flow pattern during Tohoku EQ}

The wind is one of the prominent topospheric status index, dictated by temperature, humidity and pollutants embedded in the media. Therefore, wind flow pattern is expected to undergo modifications by an earthquake specially a massive one like that of Tohoku. Further, with the positive responses of the tropospheric parameters to this event, as observed, we are encouraged to examine here the wind flow pattern around the epicenter and to identify anomalous modes of flow if induced by the earthquake preparatory processes. Figures 12 (a,b) present a normally observed wind pattern to Japan, during equinoxial month. Clear and strong parcel of cold winds that flow from higher latitudes (extending to polar zone) to Japan is obvious. These features are then compared with those provided by hyper split model and the wind flow model outputs are presented in Figure 13, prior to, during and after the Tohoku event. One can note that the expected (i.e. wind to flow from higher latitudes with clear non dispersive parcel mode) circulation pattern was maintained up to the $5^{\text {th }}$ March (Figures $13 \mathrm{a}, \mathrm{b}$ ) but from March 6 , the wind flow modes get modified. Instead of a clean well formed parcel of wind from the polar zone, the stream gets diverged and sources get shifted downwards away from pole (Figures13, c, d and e). Along with the shift, streams of additional wind flow developed almost at the same latitude of the epicenter but $4^{\circ}$ to $5^{\circ}$ west of the epicenter, more significant as the day approaches the Tohoku event when this additional wind flow features become more visible. -This pattern we call EQ time localized wind which continued to March 11 (Figures $13 \mathrm{f}, \mathrm{g}, \mathrm{h}, \mathrm{i}$ ).

The anomalous flow disappeared after the event with restoration of normal wind circulation from higher latitudes even from latitudes as high as $45^{\circ} \mathrm{N}$, (Figure 14). However, the thermo dynamical environments 
that govern wind flow are not simple. In this connection perhaps $\mathrm{Cn}^{2}$ profile that we have presented in Figure 11, could offers the type of complexity as seen from equations 4 and 5.Though presence of multivariabilities make the environment complex, the dictating prominent parameters being temperature $(\mathrm{T})$ and humidity, an increase in EQ time temperature will decrease the magnitude of $\mathrm{Cn}^{2}$, which we have observed in this event (Figure 11). Thus, a localized increase in temperature (heating) is likely to generate a local wind circulation resulting to growths of additional flow from a relatively short distance as seen prior to this Tohoku earthquake.
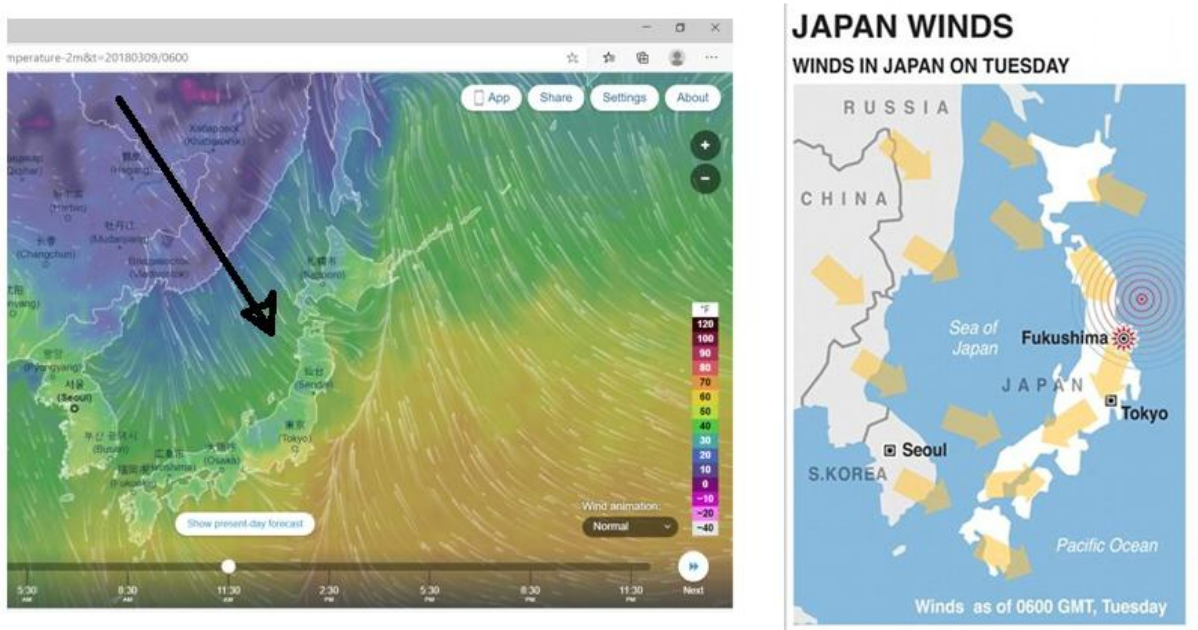

Figures $12(\mathrm{a}, \mathrm{b})$ : Presents a normally expected wind flow pattern of Japan, during equinoxial month . Note presence of strong and well defined parcels of cold wind flow from higher latitudes (extending to polar zone) to Japan.
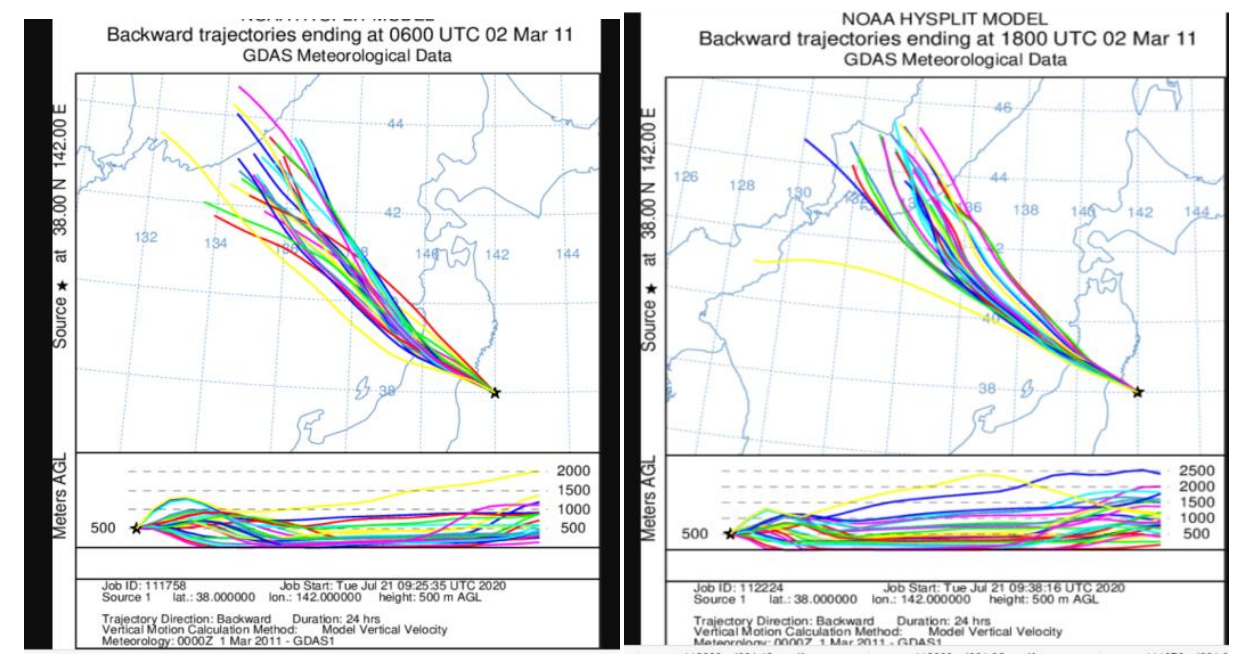


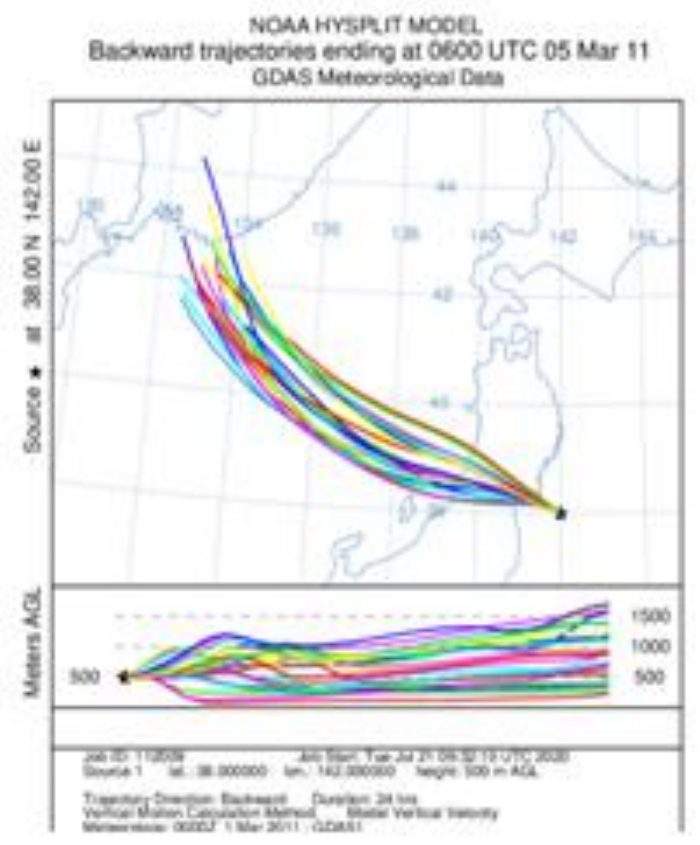

Figures 13 (a,b and c): Show model outputs of wind flow patterns to Japan, before the Tohoku earthquake. Note presence of the normally expected flow with parcel of cold winds from higher latitudes.
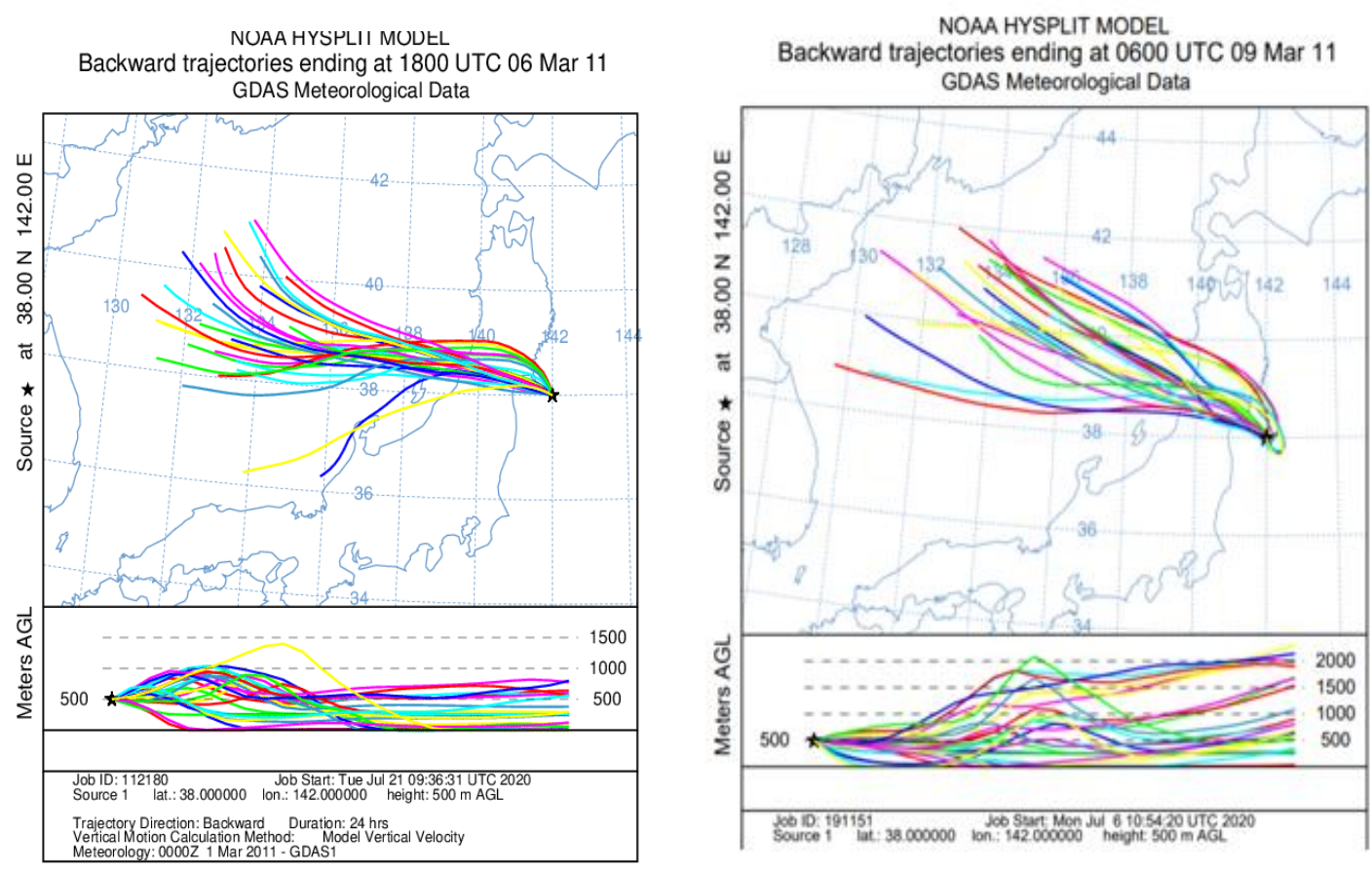

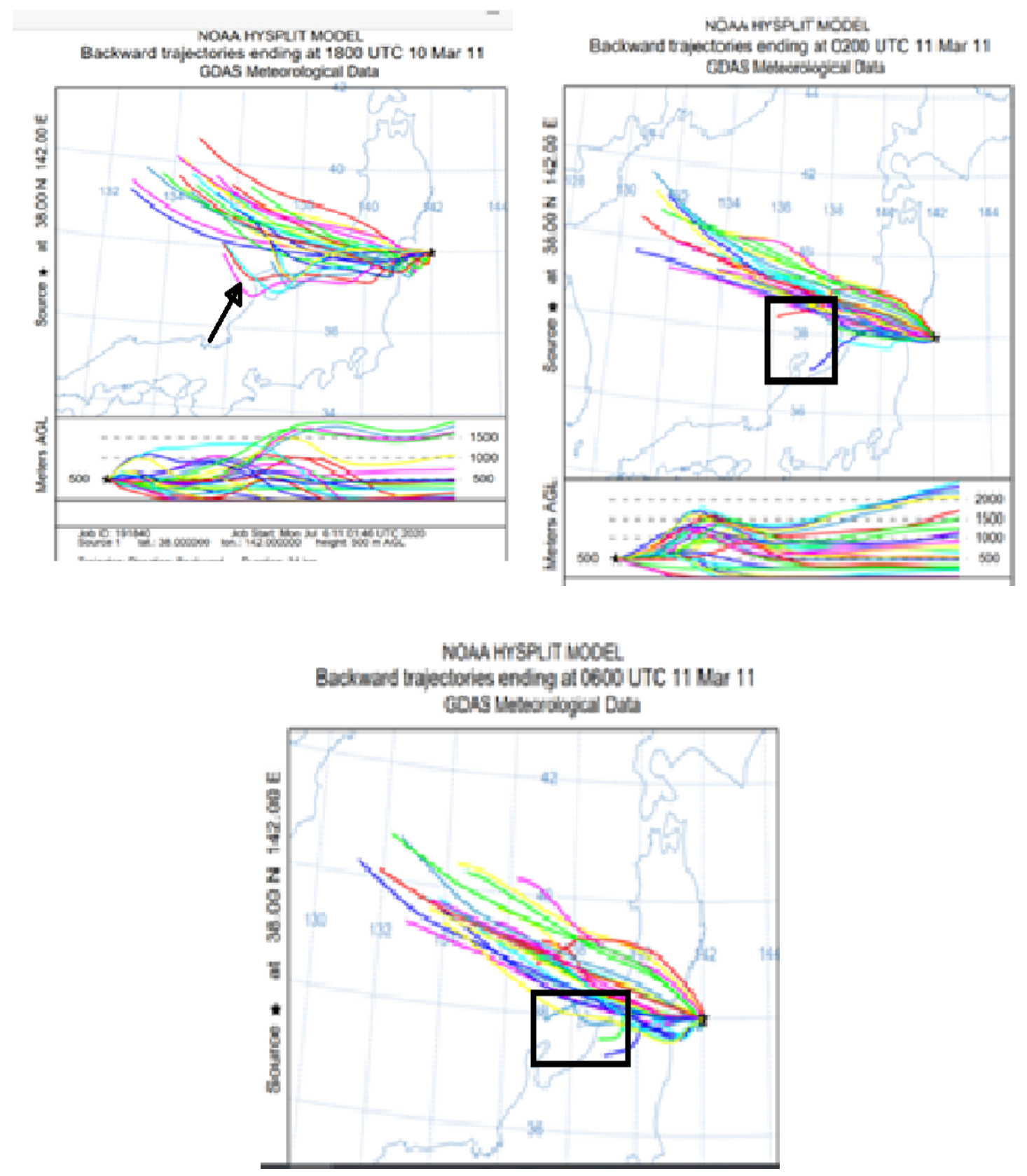

Figures 13 (d,e,f,g,h ,i ): Show model outputs of wind flow patterns to Japan, (d,) 5 days' before the Tohoku earthquake; (e ) two days before the EQ but on the day of strong foreshock event of $M=7,3$ (note sudden absence of extra wind component); (f,g ) one day prior to and $(\mathrm{h}, \mathrm{i})$ just before the Tohoku EQ. 


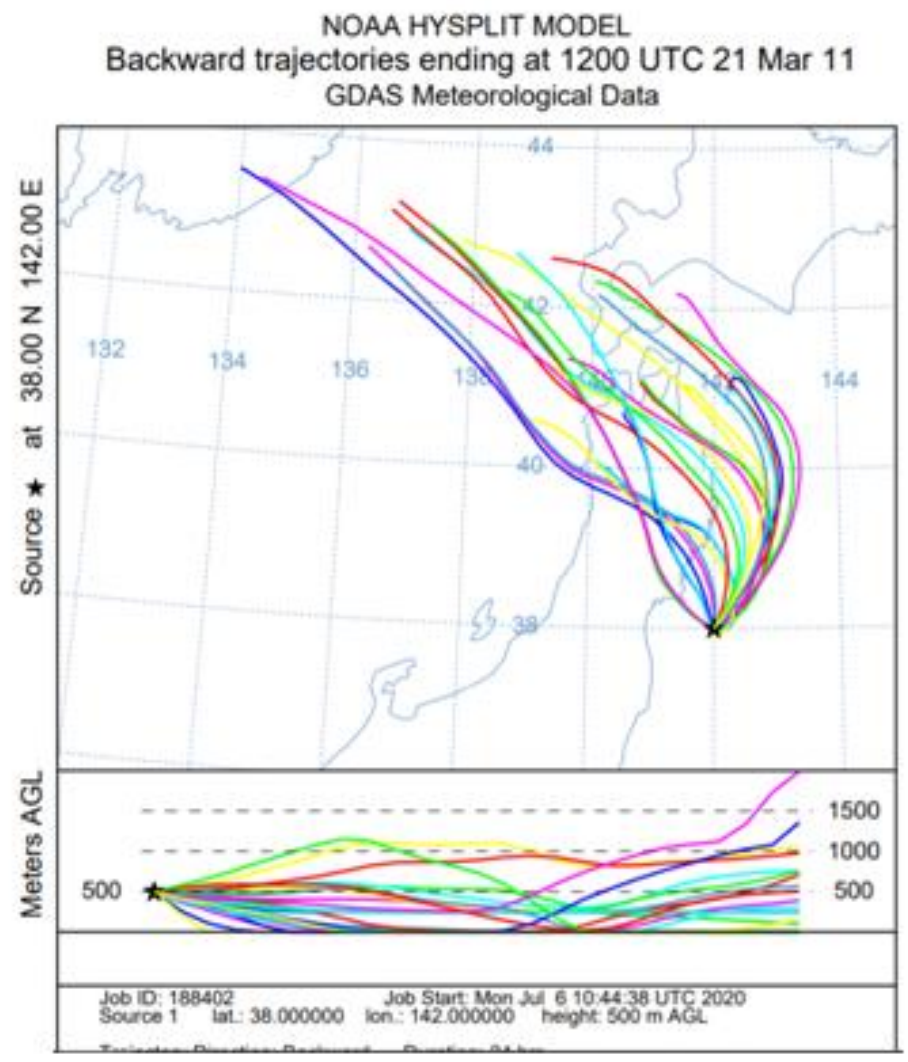

Figure 14: Disappearance of extra wind components and appearance of the normally expected wind flow pattern after the EQ, with parcel of cold winds from higher latitudes.

Interesting to note the synchronization of the days between appearance (disappearance) of growth on anomalous TEC at the longitude zone of the epicenter and the days of appearance (disappearance) of extra short distance EQ time wind flow.But the explanation needs further involved analysis and more case studies to be conducted to find the physics involved..

\section{Discussions and conclusions}

In the introduction of the paper, emphases are given on the availability of innumerable studies with multiple parameters from earth crust to atmosphere and beyond, based on Tohoku EQ .This paper also brought out a few features of the atmosphere modified by the preparatory processes of the Tohoku event such as : (i) development of Earthquake time Equatorial Anomaly, though the epicenter was at the low 
mid latitude position; (ii) Indirect role of troposphere towards changes in magnitudes of TEC and (iii) direct effect on Tropospheric physical parameters like RRI, $\mathrm{Cn}^{2}$ and wind flow pattern.

One of the key factors towards changes in TEC during low latitude EQ, is by EXB processes where ionospheric E field gets modified by seismic induced field [Anderson et al., 2002; Devi et al., 2004; Devi et al., 2011; Ryu et al., 2014 ; Fan et al ., 2015 ; Ryu et al., 2016 ; Devi et al., 2018]. However, in this Tohoku event, though its epicenter was at mid latitude, the development of Earthquake time Equatorial Anomaly (EEA), was clear and distinct even in the night sector of the epicenter longitude zone [Devi and Barbara 2012(a); Devi et al., 2013; Ryu et al., 2014; Ryu et al., 2016]. This finding is important, because the anomalous appearance of satellites that carry large TEC values, as displayed in Figures 9 and 10, was associated to changes in tropospheric parameters. Thus the indirect contribution of troposphere in enhancing the Ionospheric density provides the presence of TI (TroposphericIonospheric) coupling mode. Perhaps the synchronization between development of EEA from $6^{\text {th }}$ March at the longitude zone of the Tohoku epicene and the date of modification in wind circulation pattern is significant in this context. No doubt, the release of energy-built up process by the EQ preparatory actions as starts a few days prior to the striking of an EQ, similar the gradual building up of EQ induced field. Thus, an apparent association in tine is likely to exist between EQ signatures seen at the troposphere and in the upper atmosphere, especially during a massive EQ like Tohoku. It is perhaps also important to note that the source of this anomalous wind flow lies at the epicenter latitude but around $4^{\circ}$ west of it and falls within the locations where relatively strong ionopsheric responses to EQ (Figure 6) were observed. Thus, existence of association between troposphere wind flow pattern and modification in density during this EQ is though apparent, more study is needed to substantiate this mode of coupling dynamics.

The presence EQ signature at the troposphere is also strengthened by Earthquake time $\mathrm{Cn}^{2}$ feature, which further provides input support towards explanation on development of seismic time localized short distance wind flow. In this aspect we may refer to the reports on development of EQ time meteorological phenomenon like earthquake clouds around the epicenter [Harrington and Shou 2005; Devi et al., 2007; Harrison et al., 2013], which is explained through release of vapour from the interior stress zone, condenses at the near earth environment forming cloud around, where again temperature becomes the prime mover. In our observation here, the additional wind flow from the latitudes near to the epicenter but around $200 \mathrm{~km}$ away, could be coupled to horizontal temperature gradient caused by EQ involved temperature, as also seen indirectly in $\mathrm{Cn}^{2}$ parameter. Perhaps the wind component is formed with vertical 
shear which is a function of horizontal temperature gradient, i.e., changes in temperature over some horizontal distance (we may call thermal localized), in this case between the epicenter and the source at $200 \mathrm{~km}$, The disappearance of the localized ( as identified ) flow ( Figures see March 10 and March 25) might suggest that the along with the changes in temperature gradient, the polar wind flow pattern gets changed and moves up in latitude towards equator. It is also suggested that as the main island of Japan had suffered a shift of 2.4 meters along with modifications at the floor ( during Tohoku EQ), it is also possible that sea currents might get modulated by it and resulting to changes in local weather situation.

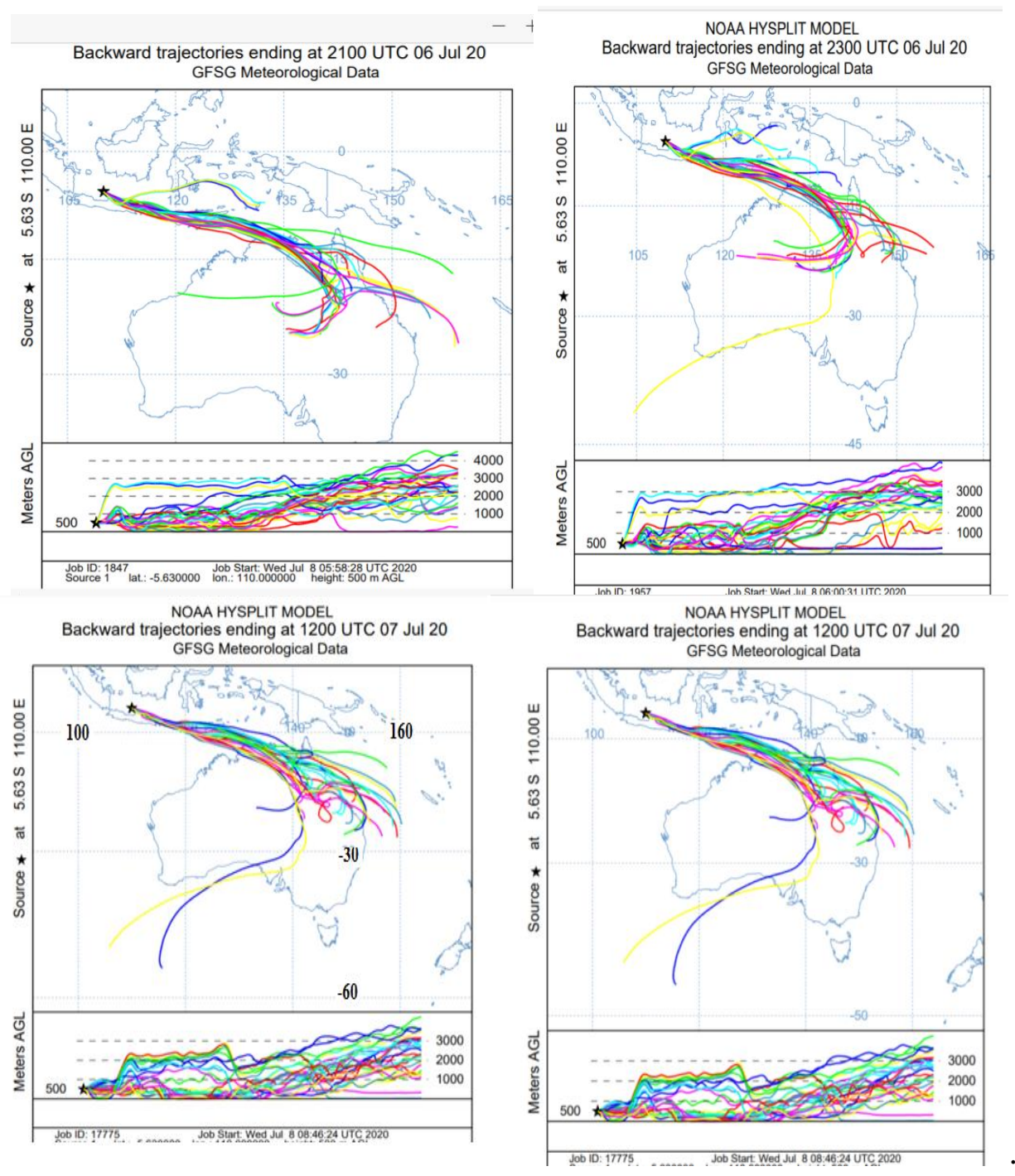

Figure 15: Shows model output of wind flow pattern around Indonesia: (a,) just prior to and (b) during July 6 the Indonesia EQ ; ( $c$ and d) : appearance of the normally expected wind flow pattern after the EQ, with parcel of cold winds from higher latitudes. 
As supports to these observational views and aspects, we may refer to the wind circulation system prior to and during the Indonesia EQ of magnitude of $\mathrm{M}=6,6$ with epicenter at $5.63^{\circ} \mathrm{S}, 110.67^{\circ} \mathrm{E}$ that occurred on 06.07.2020 at 22:54:47 UTC .In this event too, the wind circulation features show (model computed) development of an extra wind flow at the latitude of epicenter but $2^{\circ}$ east of it ( as per our definition localized flow) just before the EQ ( Figure 15a) and continued to flow till 2300 UTC and then disappeared after the event . The pole ward winds then started to grow as seen on July $7^{\text {th }}$ and these components gradually take significant role in the wind circulation process as normal feature (Figure 15b), However, more cases are to be studied before the final conclusion could be drawn.

\section{Acknowledgements:}

The authors Devi, Barbara and Depueva acknowledge with thanks the DST, India for supporting the work thorough RFBI project. The Mitsubishi foundations of Japan were duly acknowledged by Devi and Oyama for the offer of partial financial assistances to this joint programme.

\section{Reference}

Anderson, D., Adela, A., Kiyohumi , Y., Ishitsuka,M., Kudeki, E., Estimating daytime vertical ExB drift velocities in the equatorial F-region using ground-based magnetometer observations. Geophysicla Research letter, 29, 12, 37-1-37-4, 2002.

Depueva, A.H., Mikhailov, A.V., Devi, M., Barbara, A.K., Spatial and time variations in critical frequencies of the ionospheric $\mathrm{F}$ region above the zone of equatorial earthquake preparation. Geomagn. Aeron, 47, no.1, 129-133, 2007, https://doi.org/10.1134/S0016793207010197.

Devi, M., Barman, M.K., Barbara, A.K., and Depueva, A.H., Total electron content near anomaly crest as precursor of earthquake. Ind. J. Radio Space Physics, 30, 209-213, 2001.

Devi, M., Barbara, A.K., and Depueva, A.H., Association of Total Electron content and foF2 variations with earthquake events at the anomaly crest region. Annals of Geophysics, 47, 83-91, 2004.

Devi, M., Barbara, A. K., Ruzhin, Yu. Ya. and Depueva, A., Beyond the Horizon Propagation of VHF Signals. Atmospheric Features and Earthquake, Electronic Journal. Investigated in Russia, 129e, No. 39, 1331-1340, 2007.

Devi, M., Barbara, A. K., Depueva, A., and Depueva, V., Preliminary results of TEC measurements in Guwahati, India. Advances in Space Research, 42, 753-756, 2008. 
Devi, M., Barbara, A.K., Kashyap, P., Depueva, A., Ruzhin, Y.Y., Depuev, V., Earthquake time low latitude total electron content (TEC) variations and model based pattern: identification of earthquake induced atmospheric dynamics. Adv Geosciences, 27, 69-84, 2010a.

Devi, M., Barbara, A.K., Depueva, A.H., Ruzhin, Yu.Ya., Depuev, V., Anomalous Total Electron Content (TEC) and atmospheric refractivity prior to very strong China earthquake of May 2008. International Journal of Remote Sensing, 3, 3589 - 3599, $2010 \mathrm{~b}$.

Devi, M., Sarma, A. J. D., Kalita, S., Barbara, A. K., Depueva, A., Adoptive techniques on extraction of preseismic parameters on Total Electron Content (TEC) at anomaly crest stations using GPS data. Geomatics, Natural Hazards and Risk, 2011, doi:10.1080/19475705.2011.595831.

Devi, M. and Barbara, A.K., Total electron content and anomalous appearance of GPS satellites as pointers to epicentre identification of major Japan earthquake of 2011. Positioning, 3, no.1,7-12, 2012. https://doi.org/10.4236/pos.2012. 31002.

Devi, M., Barbara, A. K., Ruzhin, Ya. Yu. and Hayakawa, M.,Over-the-Horizon Anomalous VHF Propagation and Earthquake Precursors Surv Geophys, An International Review Journal Covering the Entire Field of Geosciences and Related Areas, 2012, DOI 10.1007/s10712-012-9185-z

Devi, M., Medhi, A., Sarma, A.J. D., Barbara, A.K ., Growth and inhibition of equatorial anomaly prior to an earthquake (EQ): case studies with total electron content (TEC) data for major EQs of Japan 2011 and Indonesia 2012, Positioning , 4, no.3, 240-252, 2013, https://doi.org/10.4236/pos.2013.43024.

Devi , M., Barbara, A. K., Oyama, Ko-Ichiro., Chen, Chia-Hung, Earthquake induced dynamics at the ionosphere in presence of magnetic storm. Advances in Space Research, 53, Issue 4, 609-618, 2014.

Devi, M., Barbara, A.K., Oyama, K.I., Ryu, K., Chen, C.H., Kodama,T., Expansion of earthquake (EQ) time equatorial anomaly: an index of precursor as seen in major Nepal EQ of April 2015. Int. Journal of .Electron. Appl. Res, 2, no.2, 46-59, 2015a. https://doi.org/10.33665/IJEAR.2015.v02i02.002

Devi, M., Medhi, A., Barbara, A.K., DepuevaA., Ruzhin, Yu., Orographic role in Anomalous VHF propagation on the background of impending earthquakes. Annals of Geophysics, vol.58, no.3. A0333, 2015 b, doi:10.4401/ag-6716

Devi, M., Patgiri, S., Barbara, A. K., Oyama, K.I., Ryu, K., Depuev, V., Depueva, A, Role of Equatorial Anomaly in Earthquake time precursive features: A few strong events over West Pacific zone, Advances in space research, 61, Issue -6, 1444-1455, 2018, https://doi.org/10.1016/j.asr.2018.01.003.

Devi, M., Barbara, A.K., Patgiri, S., Depueva, A., Medhi, A., Oyama, K., Depueve, V. and Ruzhin, Ya. Yu., Atmospheric waves as Earthquake precursive tools in Lithospheric Tropospheric Ionospheric coupling dynamics. International Journal of Electronics and Applied Research (IJEAR), ISSN no: 2395 0064, Vol. 6, issue 1, 2019a, https://doi.org/10.33665/IJEAR.2019.v06I01.004. 
Devi, M., Barbara, A.K., Patgiri, S., Depueva , A. , Oyama, K., Depueve , V,and Ruzhin, Ya. Yu., Perturbation Features imprinted on Ionosphere by successive clusters of Strong earthquakes: Role of atmospheric coupling dynamics. Geomagnetism and Geoelectric 8, No 7, 955-970, 2019b.

Dobrovolsky, I.R., Zubkov, S.I., and Myachkin, V.I., Estimation of the size of earthquake preparation zones. Pure and Applied Geophysics, 117, 1025-1044, 1979.

Fan, Y., Du, X., A.N., Zhanghui, Liu, J. Y, Tan, D., Chen, J., Earthquake-related Electric Field Changes Observed in the Ionosphere and Ground. Acta Geophysica, 63, no. 3, 679-697, 2015, DOI: 10.1515/acgeo-2015-0015

Gershenzon, Naum \& Gokhberg, M.B., On the origin of anomalous ultra-low frequency geomagnetic disturbances prior to the Loma Prieta, California, earthquake. Phys. Solid Earth. 30. 112-118, 1994.

Harrington, D. and Shou, Z., Bam Earthquake Prediction \& Space Technology Seminars of the United Nations Programme on Space Applications. Selected Papers from Activities Held in 2004. United Nations, New York, ISBN 92-1-100935-9, p.39, 2005.

Harrison, R. G., Aplin, K. L., and Rycroft ,M. J., Earthquake-cloud coupling through the global atmospheric electric circuit, Nat. Hazards Earth Syst. Sci., 1, 7271- 7283, 2013.

Liu, J.Y., Chen, Y.I., Chou, Y.J., Tsai H.F., Variations of ionospheric total electron content during the Chi-Chi earthquake. Geophys. Res. Lett., 28, 1383-1386, 2001.

Liu, J. Y., Chen, C. H., Chen, Y. I., Wan, W. H., Oyama, K. I., and Kuo, K. W., A statistical study of ionospheric earthquake precursors monitored by using equatorial ionization anomaly of GPS TEC in Taiwan during 2001-2007, J. Asian Earth Sci., 39, 76-80, 2010.

Liu, J.Y., Chen, C. H., and Tsai H. F., A statistical study on ionospheric precursors of the total electron content associated with $146 \mathrm{M}>6.0$ earthquakes in Japan during 1998- 2011. Earthquake Prediction Studies: Seismo Electromagnetics, edited by Hayakawa, 1-13, 2014. TERRAPUB

Medhi, A., Devi, M., Goswami, H. J., Barbara, A. K., Atmospheric turbulences over Guwahati and their association with tropospheric dynamics, IJRSP, 35-44, 2015.

Medhi, A., Earthquake induced anomalous atmospheric phenomena and their effects on signal propagation relevant to ne environment, (Chapter V), PhD Thesis, Gauhati University, Dept of Physics, 2016, http://hdl.handle.net/10603/143295.

Medhi, A., Devi, M., Barbara, A. K., Depueva A., Adoptation of atmospheric structure constant $\left(\mathrm{Cn}^{2}\right)$ for identification of boundary layer height: relevant to hazard monitoring, International Journal of Electronics and Applied Research (IJEAR), ISSN no: 2395-0064, Vol. 5, 46-61, 2018.

Ouzonov, D., and Freund, F., Mid-Infrared emission prior to strong earthquakes analyzed by remote sensing data. Advances in Space Research, 33, 268-273, 2004. 
Oyama, K. I., Kakinami Y., Liu J. Y., Kamogawa M., and Kodama T., Reduction of electron temperature in lowlatitude ionosphere at 600km before and after large earthquakes. J. Geophys. Res., 113, A11317, 2008.

Oyama, K. I., Kakinami Y., Liu J. Y., Abdu M. A., and Cheng C. Z., Anomalous Ion Density Latitudinal Distribution as a precursor of large earthquake. J. Geophys. Res., 116, A04319, 2011.

Oyama, K. I., Chen C. H., Bankov L., Devi, M, Ryu K., Liu J. Y. and Liu H., Precursor effect of March 11, 2011 off the coast of Tohoku earthquake on high and low latitude ionospheres and its possible disturbing mechanism. Adv. Space Res., 63, 2623-2637, 2019,https://doi.org/10.1016/j.asr.2018.12.042

Oyama, K.I ., Devi M., Ryu K., Chen C. H., Liu J. Y., Liu H., Bankov L.and Kodama T., Modifications of the ionosphere prior to large earthquakes: report from the Ionosphere Precursor Study Group, Geosci. Lett. 3:6, 2016, DOI 10.1186/s40562-016-0038-3.

Parrot, M., and Li M., Statistical analysis of the ionospheric density recorded by the DEMETER satellite during seismic activity, in "Pre-Earthquake Processes: A multi disciplinary approach to earthquake prediction studies", Ed. by D. Ouzounov et al., AGU Monograph, 319-328, 2018.

Pulinets, S and Boyarchuk K, Ionospheric Precursors of Earthquakes, Springeer, Berlin. p315, 2004.

Ryu, K., Lee, E., Chae, J. S., Parrot, M., Oyama, K.I., Multisatellite observations of an intensified equatorial ionization anomaly in relation to the northern Sumatra earthquake of March 2005. J. Geophys. Res., 119, 47674785, 2014.

Ryu ,K., Oyama , K.I., Bankov, L., Chen , C.H., Devi , M., Liu, H., Liu , J Y., Precursory enhancement of EIA in the morning sector Contribution from midlatitude large earthquakes in the north-east Asian region. Advances in Space Research, 57, 268-280, 2016.

Smirnov, V.M., Smirnova, E.V., Ruzhin, Yu. Ya., Tynyankin, S.I. and Skobelkin, V.N., Hardware-software complex for monitoring and research of the artificial and nature ionosphere disturbance. International Journal of Electronics and Applied Research (IJEAR), 2, issue 2, 1-13, 2015.

Sun, Y.Y., Oyama K. I., Liu J. Y., Jhuang H. K., and Cheng C. Z., The Neutral Temperature in the Ionospheric Dynamo Region and the Relation with the Ionospheric Density during Wenchuan and Pingtung Earthquakes, Nat. Hazard. Earth Syst. Sci., 11, 1759- 1768, 2011.

Takla, E.M., Yumoto K., Okano S., Uozumi T., and Abe S., The signature of the 2011 Tohoku mega earthquake on the geomagnetic field measurements in Japan, NRIAG J. Astro. \& Geophys., 2, 185-195, 2013.

Tadanori Ondoh, Ionospheric disturbances associated with great earthquake of Hokkaido southwest coast, Japan of July 12, 1993, Physics of the Earth and Planetary Interiors, 105, 3-4, 1998, 261-269, 1998. 